\title{
A Significant Role of MoO3 on the Optical, Thermal, and Radiation Shielding Characteristics of B203- P205 -Li20 Glasses
}

kh.S. Shaaban ( $\square$ khamies1078@yahoo.com )

faculty of science al azhar university at assiut https://orcid.org/0000-0002-5969-3089

\section{Research Article}

Keywords: MoO3, XRD Spectroscopic, DTA, Attenuation

Posted Date: September 13th, 2021

DOI: https://doi.org/10.21203/rs.3.rs-616462/v1

License: (c) (i) This work is licensed under a Creative Commons Attribution 4.0 International License.

Read Full License 


\title{
A Significant Role of $\mathrm{MoO}_{3}$ on the Optical, Thermal, and Radiation Shielding Characteristics of $\mathrm{B}_{2} \mathrm{O}_{3}-\mathrm{P}_{2} \mathrm{O}_{5}-\mathrm{Li}_{2} \mathrm{O}$ Glasses
}

\author{
Kh. S. Shaaban', \\ ${ }^{1}$ Chemistry Department, Faculty of Science, Al-Azhar University, P.O. 71452, Assiut, Egypt
}

\begin{abstract}
Glasses based on borophosphate with the formula $42.5 \mathrm{P}_{2} \mathrm{O}_{5}-42.5 \mathrm{~B}_{2} \mathrm{O}_{3}-(15-\mathrm{x}) \mathrm{Li}_{2} \mathrm{O}-\mathrm{xMoO}$ mol\% where $x=(0 \leq x \geq 15)$ were manufactured using the melt-quenching methodology. The status of prepared samples was identified by (XRD). The temperature of the glass transition $T_{g}$, the temperature of onset glass crystallisation $T_{c}$ and the temperature of the crystallisation $\mathrm{T}_{\mathrm{p}}$ were evaluated using a differential thermal analyser (DTA). The energy gap $\left(E_{\text {opt }}\right)$, Urbach $\left(E_{u}\right)$, and parameters of dispersion were calculated through the data of optical spectra. Physical properties were determined and calculated, such as molar refractivity, metallization, electron polarizability, electronegativity, loss of reflection and dispersion parameters. Raising $\mathrm{MoO}_{3}$ at the expense of $\mathrm{Li}_{2} \mathrm{O}$ was used to assess the level of protection. For radiation protection applications, the glasses under investigation had superior characteristics.
\end{abstract}

Keywords: $\mathrm{MoO}_{3}$, XRD Spectroscopic, DTA, Attenuation.

*Corresponding Author: Email: khamies1078@yahoo.com 


\section{Introduction}

$\mathrm{B}_{2} \mathrm{O}_{3}-\mathrm{P}_{2} \mathrm{O}_{5}$ glasses with superior efficiency can be used in a variety of different settings. Solid-state batteries, and nonlinear optics borophosphate glasses are appropriate. Due to its obvious advantages, lithium borophosphate is classical glass that has become recognized in storage batteries. These glasses are used as storage batteries in optical and electronic instruments. The addition of modifiers such as $\mathrm{Li}_{2} \mathrm{O}$ influences of these characteristics. $\mathrm{Li}_{2} \mathrm{O}$ will be combined instead of $\mathrm{B}$-change $\mathrm{BO}_{4}$ to $\mathrm{BO}_{3}[\mathbf{1 - 8}]$. The characteristics of the combined glass $\left(\mathrm{B}_{2} \mathrm{O}_{3}+\mathrm{P}_{2} \mathrm{O}_{5}\right)$ networks vary from those of the single glass $\mathrm{B}_{2} \mathrm{O}_{3}$ and $\mathrm{P}_{2} \mathrm{O}_{5}$ networks.

Transition metal oxides (TMOs) are a fascinating group of semiconductor materials because of their technological advantages for use in microelectronics and display systems. $\mathrm{MoO}_{3}$ among (TMOs), due to its excellent use in optical materials and electrochemical devices has received increasing attention in recent years. There is a goal that support in manufacturing these glasses regarding the $\mathrm{MoO}_{3}$ used in these implementations. Different $\mathrm{MoO}_{3}$ preparation glasses were developed and investigated in response to this broad range of applications [9-16].

Due to the existence of $\mathrm{MoO}_{4}$ and $\mathrm{MoO}_{6}$ in the glass network, $\mathrm{MoO}_{3}$ appears as the former non-conventional network. The existence of $\mathrm{MoO}_{3}$ in glass systems does have a modifier impact on UV spectra [9-16]. There are increasingly diverse technologies for molybdenum borophosphate-based glasses, such as laser host fibers and superconducting switches.

Both scientifically and technologically, the significant advances of alkaline borophosphate glasses are considerable. The existence of $\mathrm{PO}_{4} \& \mathrm{BO}_{4}$ structural units, this consequence approaches from the structural issues connected with covalent links. In several fields, $\mathrm{B}_{2} \mathrm{O}_{3}-\mathrm{P}_{2} \mathrm{O}_{5}-\mathrm{Li}_{2} \mathrm{O}-\mathrm{MoO}_{3}$ glasses possess high applications because of their radiation shielding and good FT-IR transmission [17-33]. The object of this study is to assist you in the 
preparation of $\mathrm{B}_{2} \mathrm{O}_{3}-\mathrm{P}_{2} \mathrm{O}_{5}-\mathrm{Li}_{2} \mathrm{O}-\mathrm{MoO}_{3}$ glasses and investigating their optical and neutron shielding using Phy-X/PSD [34] properties.

\section{Methodology}

Table 1 shows how we formed the glasses in our published articles using the meltquenching methodology. By melting together of $\mathrm{B}_{2} \mathrm{O}_{3}$ in its $\mathrm{H}_{3} \mathrm{BO}_{4}$ (Merck), $\mathrm{Li}_{2} \mathrm{O}$ in it $\mathrm{Li}_{2} \mathrm{CO}_{3}$ (Aldrich), $\mathrm{P}_{2} \mathrm{O}_{5}$ in it $\left(\mathrm{NH}_{4}\right)_{2} \mathrm{HPO}_{4}$ (Merck) and $\mathrm{MoO}_{3}$ (Merck) in an o pen ceramic crucible. With the evaporation of $\mathrm{CO}_{2}, \mathrm{NH}_{3}$ and $\mathrm{H}_{2} \mathrm{O}, \mathrm{Li}_{2} \mathrm{CO}_{3},\left(\mathrm{NH}_{4}\right)_{2} \mathrm{HPO}_{4}$ and $\mathrm{H}_{3} \mathrm{BO}_{4}$ and are converted into $\mathrm{Li}_{2} \mathrm{O}, \mathrm{P}_{2} \mathrm{O}_{5}$ and $\mathrm{B}_{2} \mathrm{O}_{3}$. The furnace temperature was changed at a melting temperature of $1050{ }^{\circ} \mathrm{C}$. At $350{ }^{\circ} \mathrm{C}$ the prepared samples are annealed.

The Philips X-ray diffractometer (model PW / 1710) checked the condition of these glasses and glass-ceramics. The spectrophotometer was used to measure the optical spectra of the investigated glass system (type JASCO V- 670). The thermal investigation was carried out with a DTA-50 (Shimadzu-Japan). Phy-X / PSD can calculate a variety of shielding considerations [34]. Electron density $\left(N_{\text {eff }}\right)$ was predictable as: $\mathrm{N}_{\text {eff }}=\mathrm{N} \frac{\mathrm{Z}_{\text {eff }}}{\sum_{\mathrm{i}} \mathrm{F}_{\mathrm{i}} \mathrm{A}_{\mathrm{i}}}$, . Effective cross-section of removal $\left(\Sigma_{\mathrm{R}}\right)$ projected as: $\left(\frac{\Sigma_{\mathrm{R}}}{\rho}\right)=\sum_{\mathrm{i}} \mathrm{W}_{\mathrm{i}}\left(\frac{\Sigma_{\mathrm{R}}}{\rho}\right)_{\mathrm{i}}$ and $\mathrm{R}=\sum_{\mathrm{i}} \rho_{\mathrm{i}}\left(\frac{\mathrm{R}}{\rho}\right)_{\mathrm{i}}$, , G-P

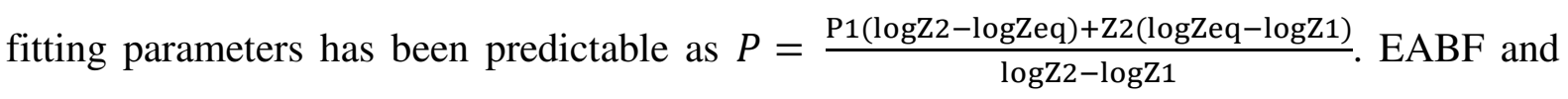
EBF were predictable using G-P fitting $B(E, X)=1+\frac{b-1}{K-1}\left(K^{x}-1\right)$ for $\mathrm{K} \neq 1, B(E, X)=$ $1+(b-1) x \mathrm{~K}=1$ where $K(E, X)=c x^{a}+d \frac{\tanh \left(\frac{x}{X k}-2\right)-\tanh (-2)}{1-\tanh (-2)}$

\section{Results and Discussion}

\subsection{XRD}

Figure 1 depicts the glass system's X-ray features. In the glass samples, XRD revealed no discrete lines or sharp peaks, indicating a high degree of glass status.

\subsection{Optical spectra}


The absorption (A), transmittance $(\mathrm{T})$, and reflectance $(\mathrm{R})$ of glass samples are shown in Figures 2 and 3. Spectral UV according to reports, increasing. As a result, $\mathrm{MoO}_{3}$ is to blame for the slight increase in BO [35-44]. Figure 4 shows the absorption coefficient of the glasses.

\subsection{1 band gap $E_{\text {opt }}$}

Glass spectrum in the UV and VIS areas were used for the estimated of the band gap energy $E_{\text {opt }}$ is estimated by $(\alpha . h v)^{1 / 2}=B\left(h v-E_{\text {opt. }}\right)$ where B is an energy independent constant and $h v$ is photon energy. By intrigue the $(\alpha . h v)^{1 / 2}$ versus $h v$ as Fig.5. Plot of $(\alpha . h v)^{1 / 2}$ against photon energy $(h v)$ to evaluate the indirect $E_{o p t}$ from the intercept. $E_{\text {opt }}$ increases with increasing $\mathrm{MoO}_{3}$, as revealed in Table 2, due to oxygen bridges (BO) form and bind excited electrons more tightly than non-bridging oxygen electrons (NBO). Urbach energy has been calculated $\propto_{0} \exp \left(\frac{h v}{E_{u}}\right)$, Fig. 6 and table 2 show that their $E_{\text {opt }}$ values have an inverse relationship. The values of $E_{\text {opt }}$ and $E_{u}$ was shown in Fig.7.

The refractive index was calculated using: $n=\frac{(1-R)^{2}+k^{2}}{(1+R)^{2}+k^{2}} \quad$ where $k=\alpha \lambda / 4 \pi$. The refractive index presented in Fig. 8 for fabricated glasses. It has already been stated that density increase, the refractive index of these samples increased. As a result, it can be directly compared to reflectance and density, and opposite to molar volume.

\subsubsection{Dispersion parameters}

As approximated, molar polarization and polarizability of glasses were computed :

$$
R_{m}=\left\langle n^{2}-1 \mid n^{2}+2\right\rangle V m, \propto_{m}=(3 \mid 4 \pi N) R_{m}, \quad \text { and } \quad \propto_{0}^{2-}=\frac{\left[\frac{V m}{2.52}\left(\frac{n^{2}-1}{n^{2}+2}\right)-\sum \propto_{c a t}\right]}{N_{o}^{2-}}
$$

Polarization was linked with the optical basicity; $\Lambda=1.67\left(1-\frac{1}{\alpha_{0}^{2-}}\right)$. Figs. 9,10\& 11 exemplifies the polarizabilities, Molar Polarizability $\propto_{m}$ and optical basicity separately of the 
samples. The refractive index is trending in the same direction with $\mathrm{MoO}_{3}$ content has been reported to enhance.

The molar refractivity as $E_{\text {opt. }} R_{m}=\operatorname{Vm}(1-\sqrt{E g / 20})$ and molar polarizability $\left(\propto_{m}\right) \propto_{m}=\left(\frac{3}{4 \pi N}\right) R_{m}$. Reflection loss $R_{L}=\left(\frac{R_{m}}{V m}\right)$. Because the molar volume decreases with $\mathrm{Mo}^{+}$, these values of $\left(R_{m}\right)\left(\propto_{m}\right)$ and $\left(R_{L}\right)$ decline. The criterion for metallization is predicted as $M=1-\frac{R_{m}}{V m}$, the metallization value increase with $\mathrm{Mo}^{+}$. The electronegativity $(\chi)$ is predicted as $\chi=0.2688 E_{\text {opt. }}$. where $E_{\text {opt. }}$ bandgap. Thus, with $\mathrm{Mo}^{+}$increasing, the electronegativity $(\chi)$ values increase. The electron polarizability is predicted as, $\propto^{\circ}=$ $-0.9 \chi+3.5$ and optical basicity $\Lambda=-0.5 \chi+1.7 . \propto^{\circ}$ and $\Lambda$ have the opposite value of $(\chi)$ so, $\propto^{\circ}$ and $\wedge$ decrease with $\mathrm{Mo}^{+}$. These items are obtainable in Table 2.

The dispersion was calculated by Wemple and Didomenico $\mathrm{E}_{\mathrm{o}}$ and $\mathrm{E}_{\mathrm{d}}$ [50-53]. The hypnosis designates explained by $n^{2}-1=\frac{E_{0} E_{d}}{E_{0}^{2}-E^{2}}$ [64-70]. The plotting of, $\left(\mathrm{n}^{2}-1\right)^{-1}$ with $(h v)^{2} E_{o}$ and $E_{d}$ predictable from the slope and intercept as shown in Figs. 12 \& 13. It mentioned that with increasing $\mathrm{MoO}_{3}, \mathrm{E}_{\mathrm{o}}$ and $\mathrm{E}_{\mathrm{d}}$ were slightly enhanced. The optical energy $E_{\text {opt }}$ that represent $E o p t=\frac{E_{d}}{2}$. Refractive Static index at infinite wavelength $\left(\mathrm{n}_{\mathrm{o}}\right)$ was estimated by $n_{0}=\sqrt{1+\frac{E_{d}}{E_{0}}}$ and the static dielectric $\varepsilon_{\infty}=n_{0}^{2}$. The oscillator's wavelength $(\lambda \mathrm{o})$ and strength $\left(S_{0}\right)$ were calculated using the following formula $n^{2}-1=\frac{S_{0} \lambda_{0}^{2}}{1-\left(\frac{\lambda_{0}}{\lambda}\right)^{2}}$. These items are obtainable in Table 3.

\subsection{DTA}

The thermal analysis (DTA) of glass samples demonstrated in Fig. 14. The temperature of the glass transition, $\mathrm{Tg}$, is $493-532 \pm 3{ }^{\circ} \mathrm{C}$. The temperature of the glass crystallisation $\mathrm{T}_{\mathrm{c}}$ starts at $537-580 \pm 3{ }^{\circ} \mathrm{C}$. The temperature of the glass crystallisation $\mathrm{T}_{\mathrm{c}}$ ends at $606-645 \pm 3{ }^{\circ} \mathrm{C}$. According to DTA observations, Tg increases from 493 into $532{ }^{\circ} \mathrm{C}$, Tc increases from 537 
into $580{ }^{\circ} \mathrm{C}$ and $\mathrm{Tp}$ increases from 606 into $645^{\circ} \mathrm{C}$ with the increase of $\mathrm{MoO}_{3}$ content. The transformation of Li-O to Mo-O linkages is significantly associated with this behaviour. Hence, $\mathrm{Li}-\mathrm{Li}(137.3 \pm 6.3 \mathrm{KJ} / \mathrm{mol})$ dissociation energy is weaker than Mo-Mo $(449.4 \pm 1 \mathrm{KJ} / \mathrm{mol})$ dissociation energy and adding $\mathrm{MoO}_{3}$ variations the basic $\mathrm{B}$ units from $\mathrm{BO}_{3}$ to $\mathrm{BO}_{4}$. Thermal stability estimated by $\Delta T=(T c-T g)$, weighted thermal stability $H g=\Delta T / T g$ and $S=$ $(T p-T c) \Delta T / T g$. It observed that all thermal stability of samples improved as $\mathrm{MoO}_{3}$. The $\mathrm{T}_{\mathrm{g}}, \mathrm{T}_{\mathrm{c}}, \mathrm{T}_{\mathrm{p}}$ and thermal stability values are obtainable in Table 4.

\subsection{Photon Shielding Features}

The level of protection was assessed in this article by increasing $\mathrm{MoO}_{3}$ at the expense of $\mathrm{Li}_{2} \mathrm{O}$ with the composition $42.5 \mathrm{~B}_{2} \mathrm{O}_{3}-42.5 \mathrm{P}_{2} \mathrm{O}_{5}-(15-x) \mathrm{Li}_{2} \mathrm{O}-x \mathrm{MoO}_{3}, \quad(0 \leq x \geq$ 15). The mean free path (MFP) is depicted in Fig.15. It was stated that as photon energy increases, the values of (MFP) increase. This insight revealed that as the photon's energy increases, it becomes capable of transmitting samples on purpose. Because the lower value of the (MFP) sample has a higher MoO3 content, good radiation attenuation glasses are available. [54-71].

Figure 16 demonstrations the $\left(N_{\text {eff }}\right)$ of fabricated glasses. It is demonstrated that $\left(N_{\text {eff }}\right)$ decreases and then rises as energy increases. This significant decrease can be attributed to the interaction of Compton scattering. The effect of forming pairs at higher energy levels as $\mathrm{MoO}_{3}$ is linked to the increasing in $\left(N_{\text {eff }}\right)$.

The ASC of fabricated glasses are presented in Fig. 17. The ASC and ESC values are expected to decrease as energy rates increase. This decrease occurs due to the Compton scattering interaction. The $C_{\text {eff }}$ of fabricated glasses depicted in Figure 18. With the increase in photon energy, it is predicted that $C_{\text {eff }}$ will decrease. The impact of pair-creation was reflected in the increase in $C_{e f f}$. 
The EBF \& EABF of fabricated glasses were characterized by Figs. 19\&20. EBF and EABF values are determined by the lower energy and concentration of the glass samples. At lower energy levels, EBF and EABF values are low, but they rise as energy levels rise. After that, gradually decrease as energy level rises. So, we can divide the energy scale into three parts low, medium, and high. The first part (low energy): the typical phase is the photoelectric effect, and the relationship is reversed with light, and the glasses will absorb the energy photons. The photons are therefore not allowed to build-up. In the second part (medium energy): the common process is the Compton scattering, the values of EBF and, EABF is increased in all samples independent from the MFP. Through this part, the photons stay in the samples for a long time, as these processes lead to high accumulation value due to multiple scattering processes. Third parts (high energy): the common process is the pair production. In this process, EBF and, EABF is decreased with energy. Therefore, these data helped in the determination of maximum radiation intensity occur. In this research, highest radiation occurs on the surface of the sample. In Fig. 21, fast cross section neutron removal (FNRCS) is shown. It was stated that MoO3 improved FNRCS.

\section{Conclusions}

In the existing research, molybdenum lithium borophosphate glasses $42.5 \mathrm{P}_{2} \mathrm{O}_{5}-42.5 \mathrm{~B}_{2} \mathrm{O}_{3}-$ $(15-\mathrm{x}) \mathrm{Li}_{2} \mathrm{O}-\mathrm{xMoO}_{3}$ where $x=(0 \leq x \geq 15)$ were fabricated with conventional meltquenching procedures. The optical, thermal, and shielding factors were observed. The findings showed the following objects:

1- Because of the increase in $\mathrm{MoO}_{3}$, the metallization of these glasses was improved.

2- The 2.23 for $G 1,2.32$ for $G$ 2, 2.38 for $G 3,2.41$ for $G$, and 2.49 for $G 5$ were identified as the indirect optical bands that were collected.

3- Urbach energies of these samples were reduces as the content of $\mathrm{MoO}_{3}$ increase.

4- As the density of the investigated glasses rises, the refractive index rises as well. 
5- These glasses were investigated for molar polarization, polarizability, and optical basicity.

6- $\mathrm{T}_{\mathrm{g}}, \mathrm{T}_{\mathrm{c}}, \mathrm{T}_{\mathrm{p}}$ and thermal stability values are enhanced with $\mathrm{MoO}_{3}$.

7- The fabricated samples' gamma shielding features were predictable. The impact of adding $\mathrm{MoO}_{3}$ to the glasses on their shielding ability was mentioned.

8- Lower value of the (MFP) sample has more $\mathrm{MoO}_{3}$ are good radiation attenuation glasses are available.

9- As the concentration of $\mathrm{MoO}_{3}$ increased, these glasses have a high cross section neutron removal rate.

The findings discovered that as $\mathrm{MoO}_{3}$ increase the glass system can result in significant improvements in attenuation and optical characteristics. Furthermore, it is possible to use this glass in optoelectronic, optical devices, and a radiation shield for use in x-ray centers. 


\section{References}

[1] Narwal, P., Dahiya, M. S., Kundu, P., Yadav, A., Hooda, A., \& Khasa, S. Compositional dependence of properties in calcium substituted sodium borophosphate glasses containing $\mathrm{VO}^{2+}$ ions. Bulletin of Materials Science, 42(3),105-113, (2019), DOI:10.1007/s12034-019$1812-6$

[2] Khafagy, A. H., El-Adawy, A. A., Higazy, A. A., El-Rabaie, S., \& Eid, A. S. Studies of some mechanical and optical properties of $(70-\mathrm{x}) \mathrm{TeO}_{2}-15 \mathrm{~B}_{2} \mathrm{O}_{3}-15 \mathrm{P}_{2} \mathrm{O}_{5}-\mathrm{xLi}_{2} \mathrm{O}$ glasses. Journal of Non-Crystalline Solids, 354(27), 3152-3158. (2008). DOI: 10.1016/j.jnoncrysol.2008.01.013

[3] Kim, D., Hwang, C., Gwoo, D. et al. Effect of titanium on structure of sodium borophosphate glasses. Electron. Mater. Lett. 7, 343-347 (2011). https://doi.org/10.1007/s13391-011-0710-X

[4] Reddy, A. A., Babu, S. S., Pradeesh, K., Otton, C. J., \& Vijaya Prakash, G. Optical properties of highly Er3+-doped sodium-aluminium-phosphate glasses for broadband $1.5 \mu \mathrm{m}$ emission. Journal of Alloys and Compounds, 509(9), 4047-4052. (2011). DOI: 10.1016/j.jallcom.2011.01.016 
[5] Shaaban, K.S., Yousef, E.S., Mahmoud, S.A. et al. Mechanical, Structural, and Crystallization Properties in Titanate Doped Phosphate Glasses. J Inorg Organomet Polym (2020). https://doi.org/10.1007/s10904-020-01574-x

[6] Shaaban, K.S., Wahab, E.A.A., Shaaban, E.R., et al. Electronic polarizability, optical basicity, and mechanical properties of aluminum lead phosphate glasses. Opt Quant Electron 52, 125 (2020). https://doi.org/10.1007/s11082-020-2191-3

[7] Fayad, A.M., Shaaban, K.S., Abd-Allah, W.M. et al. Structural and Optical Study of CoO Doping in Borophosphate Host Glass and Effect of Gamma Irradiation. J Inorg Organomet Polym (2020). https://doi.org/10.1007/s10904-020-01641-3

[8] El-Maaref, A. A., Shimaa Badr, Shaaban, K. S., Wahab, E. A. A., \& El Okr, M. M. Optical Properties and Radiative Rates of $\mathrm{Nd}^{3+}$ Doped Zinc-Sodium Phosphate Glasses. Journal of Rare Earths. 37, 253-259 (2019). DOI: 10.1016/j.jre.2018.06.006

[9] Raza, S. H., Afzal, N., Rafique, M., Imran, M., \& Ahmad, R. Structural and morphological properties of annealed $\mathrm{MoO}_{3}$ films on different substrates. Surface Review and Letters. (2019). DOI:10.1142/s0218625x19501506

[10] Santagneli, S. H., de Araujo, C. C., Strojek, W., Eckert, H., Poirier, G., Ribeiro, S. J. L., \& Messaddeq, Y. Structural Studies of $\mathrm{NaPO}_{3}-\mathrm{MoO}_{3}$ Glasses by Solid-State Nuclear Magnetic Resonance and Raman Spectroscopy. The Journal of Physical Chemistry B, 111(34), 1010910117. (2007). DOI:10.1021/jp072883n

[11] Sivakumar, R., Manisankar, P., Jayachandran, M., \& Sanjeeviraja, C. Intercalation studies on electron beam evaporated $\mathrm{MoO}_{3}$ films for electrochemical devices. Solar Energy Materials and Solar Cells, 90(15), 2438-2448. (2006). DOI: 10.1016/j.solmat.2006.03.016

[12] Shaaban, K. S., Abo-Naf, S. M., \& Hassouna, M. E. M. Physical and Structural Properties of Lithium Borate Glasses Containing $\mathrm{MoO}_{3}$. Silicon 11, 2421-2428, (2019). DOI:10.1007/s12633-016-9519-4 
[13] Shaaban, K. S., Abo-naf S. M., Abd Elnaeim, A. M., \& Hassouna, M. E. M. Studying effect of $\mathrm{MoO}_{3}$ on elastic and crystallization behavior of lithium diborate glasses. Applied Physics A, 123(6) 457, (2017). DOI:10.1007/s00339-017-1052-9

[14] Rao, L. S., Reddy, M. S., Rao, D. K., \& Veeraiah, N. Influence of redox behavior of copper ions on dielectric and spectroscopic properties of $\mathrm{Li}_{2} \mathrm{O}-\mathrm{MoO}_{3}-\mathrm{B}_{2} \mathrm{O}_{3}: \mathrm{CuO}$ glass system. SolidState Sciences, 11(2), 578-587. (2009). DOI: 10.1016/j.solidstatesciences.2008.06.022

[15] Shaaban, K. S., \& Saddeek, Y. B. Effect of $\mathrm{MoO}_{3}$ Content on Structural, Thermal, Mechanical and Optical Properties of $\left(\mathrm{B}_{2} \mathrm{O}_{3}-\mathrm{SiO}_{2}-\mathrm{Bi}_{2} \mathrm{O}_{3}-\mathrm{Na}_{2} \mathrm{O}-\mathrm{Fe}_{2} \mathrm{O}_{3}\right)$ Glass System. Silicon, 9(5), 785-793, (2017). DOI 10.1007/s12633-017-9558-5

[16] Shaaban, K.S., Zahran, H.Y., Yahia, I.S. et al. Mechanical and radiation-shielding properties of $\mathrm{B}_{2} \mathrm{O}_{3}-\mathrm{P}_{2} \mathrm{O}_{5}-\mathrm{Li}_{2} \mathrm{O}-\mathrm{MoO}_{3}$ glasses. Appl. Phys. A 126, $804 \quad$ (2020). https://doi.org/10.1007/s00339-020-03982-9

[17] Elbers, S., Strojek, W., Koudelka, L., \& Eckert, H. Site connectivities in silver borophosphate glasses: new results from $11 \mathrm{~B}\{31 \mathrm{P}\}$ and $31 \mathrm{P}\{11 \mathrm{~B}\}$ rotational echo double resonance NMR spectroscopy. Solid-State Nuclear Magnetic Resonance, 27(1-2), 6576. (2005). DOI: 10.1016/j.ssnmr.2004.08.007

[18] Tricot, G., Alpysbay, L., \& Doumert, B. Solid State NMR: A Powerful Tool for the Characterization of Borophosphate Glasses. Molecules, 25(2), 428. (2020). DOI:10.3390/molecules25020428

[19] Koudelka, L., \& Mošner, P. Study of the structure and properties of Pb-Zn borophosphate glasses. Journal of Non-Crystalline Solids, 293-295, 635-641. (2001). DOI:10.1016/s00223093(01)00765-7

[20]Aldo Magistris, Gaetano Chiodelli, Silver borophosphate glasses : Ion transport, thermal stability and electrochemical behaviour, Solid State Ionics 9-10, (1), 611-615,1983, doi.org/10.1016/0167-2738(83)90303-X 
[21] Manzani, D., de Araújo, C. B., Boudebs, G., Messaddeq, Y., \& Ribeiro, S. J. L. The Role of $\mathrm{Bi}_{2} \mathrm{O}_{3}$ on the Thermal, Structural, and Optical Properties of Tungsten-Phosphate Glasses. The Journal of Physical Chemistry B, 117(1), 408-414. (2012). DOI:10.1021/jp3097296 [22] Taher, A. E., Ali, A. M., Saddeek, Y. B., Elsaman, R., Algarni, H., Shaaban, K., \& Amer, T. Z. Gamma ray shielding and structural properties of iron alkali alumino-phosphate glasses modified by PbO. Radiation Physics and Chemistry,165, 108403. (2019). DOI: 10.1016/j.radphyschem.2019.108403

[23] Tsuchiya, T., \& Moriya, T. Anomalous behavior of physical and electrical properties in borophosphate glasses containing $\mathrm{R}_{2} \mathrm{O}$ and $\mathrm{V}_{2} \mathrm{O}_{5}$. Journal of Non-Crystalline Solids, 38-39, 323-328. (1980). DOI:10.1016/0022-3093(80)90439-1

[24] Møller, A.P., Mousseau, T.A., The effects of natural variation in background radioactivity on humans, animals and other organisms. Biol. Rev. 88, 226-254. (2013), https://doi.org/10.1111/j.1469-185X.2012.00249.x

[25] Mettler Jr., F.A., Huda, W., Yoshizumi, T.T., Mahesh, M., Effective doses in radiology and diagnostic nuclear medicine: a catalog. Radiology 248, 254-263. (2008), doi: 10.1148/radiol.2481071451

[26] Tekin H.O., Kavaz E., Papachristodoulou A., Kamislioglu M., O. Agar, E.E. Altunsoy Guclu, Kilicoglu O., Sayyed M.I., Characterization of $\mathrm{SiO}_{2}-\mathrm{PbO}-\mathrm{CdO}-\mathrm{Ga}_{2} \mathrm{O}_{3}$ glasses for comprehensive nuclear shielding performance: alpha, proton, gamma, neutron radiation, Ceram. Int.45.15, 19206-19222, (2019), https://doi.org/10.1016/j.ceramint.2019.06.168

[27] Nowak M., Sans-Merce M., Lemesre C., Elmiger R., Damet J., Eye lens monitoring programme for medical staff involved in fluoroscopy guided interventional procedures in Switzerland, Phys. Med.57, 33-40. (2019), doi: 10.1016/j.ejmp.2018.12.001

[28] König A., Etzel R., Thomas R., Mahnken A., Personal Radiation Protection and Corresponding Dosimetry in Interventional Radiology: an Overview and Future 
Developments, RöFo - Fortschritte Auf Dem Gebiet Der Röntgenstrahlen Und Der Bildgebenden Verfahren, 191(06), 512-521. (2019), doi: 10.1055/a-0800-0113

[29] Kosaka H., Monzen H., Matsumoto K., Tamura M., Nishimura Y., Reduction of operator hand exposure in interventional radiology with a novel finger sack using tungsten-containing rubber, Health Phys. 116(5), 625-630. (2019), doi: 10.1097/HP.0000000000000992 [30] Etzel R., König A.M., Keil B., Fiebich M., Mahnken A.H., Effectiveness of a new radiation protection system in the interventional radiology setting, Eur. J. Radiol. 106. 56-61. (2018), (2018), doi: 10.1016/j.ejrad.2018.07.006

[31] Chida K., Kaga Y., Haga Y., Kataoka N., Kumasaka E., Meguro T., Zuguchi, M., Occupational dose in interventional radiology procedures, Am. J. Roentgenol. 200(1), 138 141. (2013), doi: 10.2214/AJR.11.8455

[32] Kavaz E., Tekin H.O., Agar O., Altunsoy E.E., Kilicoglu O., Kamislioglu M., Abuzaid M.M., Sayyed M.I., The Mass stopping power/projected range and nuclear shielding behaviors of barium bismuth borate glasses and influence of cerium oxide, Ceram. Int. 45. (12,15), 15348-15357. (2019), DOI: 10.1016/j.ceramint.2019.05.028

[33] Kalnins C.A.G., Ebendorff-Heidepriem H., Spooner N.A., Monro T.M., Enhanced radiation dosimetry of fluoride phosphate glass optical fbres by terbium (III) doping, Opt. Mater. Express 6 (12), 3692-3703 (2016), https://doi.org/10.1364/OME.6.003692 [34] Şakar, E., Özpolat, Öü.F1., Alım, Bü., Sayyed, M.I., Kurudirek, M., PhyX / PSD: Development of a user-friendly online software for calculation of parameters relevant to radiation shielding and dosimetry, Radiation Physics and Chemistry 166, 108496. (2020), https://doi.org/10.1016/j.radphyschem.2019.108496

[35] Shaaban, K.S., Wahab, E.A.A., Shaaban, E.R., et al. Electronic Polarizability, Optical Basicity, Thermal, Mechanical and Optical Investigations of $\left(65 \mathrm{~B}_{2} \mathrm{O}_{3}-30 \mathrm{Li}_{2} \mathrm{O}-5 \mathrm{Al}_{2} \mathrm{O}_{3}\right)$ 
Glasses Doped with Titanate. Journal of Elec Materi 49, 2040-2049 (2020). https://doi.org/10.1007/s11664-019-07889-x

[36] Abdelghany, A. M., ElBatal, F. H., Azooz, M. A., Ouis, M. A., \& ElBatal, H. A. Optical and infrared absorption spectra of $3 \mathrm{~d}$ transition metal ions-doped sodium borophosphate glasses and effect of gamma irradiation. Spectrochimica Acta Part A: Molecular and Biomolecular Spectroscopy, 98, 148-155. (2012). DOI: 10.1016/j.saa.2012.08.049

[37] Abd-Allah, W.M., Saudi, H.A., Shaaban, K.S. et al. Investigation of structural and radiation shielding properties of $40 \mathrm{~B}_{2} \mathrm{O}_{3}-30 \mathrm{PbO}-(30-x) \mathrm{BaO}-x \mathrm{ZnO}$ glass system. Appl. Phys. A 125, 275 (2019). https://doi.org/10.1007/s00339-019-2574-0

[38] Saudi, H.A., Abd-Allah, W.M. \& Shaaban, K.S. Investigation of gamma and neutron shielding parameters for borosilicate glasses doped europium oxide for the immobilization of radioactive waste. J Mater Sci: Mater Electron 31, 6963-6976 (2020). https://doi.org/10.1007/s10854-020-03261-6

[39] Abdel Wahab, E.A., Shaaban, K.S., Elsaman, R. et al. Radiation shielding, and physical properties of lead borate glass doped $\mathrm{ZrO}_{2}$ nanoparticles. Appl. Phys. A (12) 125, 869 (2019). https://doi.org/10.1007/s00339-019-3166-8

[40] Shaaban, K., Abdel Wahab, E.A., El-Maaref, A.A. et al. Judd-Ofelt analysis and physical properties of erbium modified cadmium lithium gadolinium silicate glasses. J Mater Sci: Mater Electron 31, 4986-4996 (2020). https://doi.org/10.1007/s10854-020-03065-8

[41] Shaaban, K.S., Koubisy, M.S.I., Zahran, H.Y. et al. Spectroscopic Properties, Electronic Polarizability, and Optical Basicity of Titanium-Cadmium Tellurite Glasses Doped with Different Amounts of Lanthanum. J Inorg Organomet Polym (2020). https://doi.org/10.1007/s10904-020-01640-4 
[42] Somaily, H.H., Shaaban, K.S., Makhlouf, S.A. et al. Comparative Studies on Polarizability, Optical Basicity and Optical Properties of Lead Borosilicate Modified with Titania. J Inorg Organomet Polym (2020). https://doi.org/10.1007/s10904-020-01650-2 [43] Shaaban, K. S., El Sayed Yousef, Optical properties of $\mathrm{Bi}_{2} \mathrm{O}_{3}$ doped borotellurite glasses and glass-ceramics. Optik - International Journal for Light and Electron Optics 203, 163976. (2020), https://doi.org/10.1016/j.ijleo.2019.163976

[44] Wahab, E. A. A., \& Shaaban, K. S. Effects of $\mathrm{SnO}_{2}$ on spectroscopic properties of borosilicate glasses before and after plasma treatment and its mechanical properties. Materials Research Express, 5(2), 025207, (2018). https://doi.org/10.1088/2053-1591/aaaee8

[45] Dimitrov, V., \& Sakka, S. (1996). Electronic oxide polarizability and optical basicity of simple oxides. I. Journal of Applied Physics, 79(3) 1736. doi.org/10.1063/1.360962

[46] Dimitrov, V., \& Komatsu, T. (2002). Classification of Simple Oxides: A Polarizability $\begin{array}{lllll}\text { Approach. Journal of } & \text { Solid-State } & \text { Chemistry, } & \text { 163(1) } & 100 .\end{array}$ https://doi.org/10.1006/jssc.2001.9378

[47] Zhao, X., Wang, X., Lin, H., \& Wang, Z. (2007). Electronic polarizability and optical basicity of lanthanide oxides. Physica B: Condensed Matter, 392(1-2), 132-136. 10.1016/j.physb.2006.11.015

[48] Duffy, J. A. (1989). A common optical basicity scale for oxide and fluoride glasses. Journal of Non-Crystalline Solids, 109(1), 35-39, https://doi.org/10.1016/0022-3093(89)90438-9 [49] Duffy, J. A., \& Ingram, M. D. (1992). Comments on the application of optical basicity to glass. Journal of Non-Crystalline Solids, 144, 76-80. doi:10.1016/s0022-3093(05)80385-0 [50] Wemple S.H., Didomenico M., Behavior of the Electronic Dielectric Constant in Covalent and Ionic Materials, Phys. Rev. B 3, 1338 (1971). 
[51] Abdel-Aziz, M. M., Yahia, I. S., Wahab, L. A., Fadel, M., \& Afifi, M. A. Determination and analysis of dispersive optical constant of $\mathrm{TiO}_{2}$ and $\mathrm{Ti}_{2} \mathrm{O}_{3}$ thin films. Appl. Sur. Sci., 252(23), 8163-8170, (2006).

[52] Abdel-Aziz, M. M., Metwally E.G. El-, Fadel M., Labib H.H., Afifi, M. A., Optical properties of amorphous Ge-Se-Tl system films, Thin Solid Films 386, 99 - 104, (2001).

[53] Chiad S. S., Habubi, N. F., Abass W. H., Abdul Allah M. H., Effect of thickness on the optical and dispersion parameters of $\mathrm{Cd}_{0.4} \mathrm{Se}_{0.6}$ thin films, J. of opt. elec. and adv. mat., 18, (910), 822 (2016).

[54] El-Sharkawy, R. M., Shaaban, K. S., Elsaman, R., Allam, E. A., El-Taher, A., \& Mahmoud, M. E. Investigation of mechanical and radiation shielding characteristics of novel glass systems with the composition $\mathrm{xNiO}-20 \mathrm{ZnO}-60 \mathrm{~B}_{2} \mathrm{O}_{3}-(20-\mathrm{x}) \mathrm{CdO}$ based on nano metal oxides. Journal of Non-Crystalline Solids, 528,119754, (2020), DOI: 10.1016/j.jnoncrysol.2020.

[55] El-Rehim, A.A., Zahran, H., Yahia, I. et al. (2020) Radiation, Crystallization, and Physical Properties of Cadmium Borate Glasses. Silicon. https://doi.org/10.1007/s12633-02000798-3

[56] Singh, T., Kaur, P., \& Singh, P. S. Variation of Mass Attenuation Coefficient, Effective Atomic Number, and Electron Density with Incident Photon Energy of Some Organic Acids. Nuclear Science and Engineering, 156(2), 229-243. (2007). DOI:10.13182/nse07-a2699

[57] Singh, K., Singh, H., Sharma, G., Gerward, L., Khanna, A., Kumar, R., Sahota, H. S. Gamma-ray shielding properties of $\mathrm{CaO}-\mathrm{SrO}-\mathrm{B}_{2} \mathrm{O}_{3}$ glasses. Radiation Physics and Chemistry, 72(2-3), 225-228. (2005). DOI: 10.1016/j.radphyschem.2003.11.010 
[58] Mostafa, A. G., Hassaan, M. Y., Ramadan, A. B., Hussein, A. Z., \& Abdel-Haseib, A. Y. Characterization of iron sodium phosphate glasses doped $\mathrm{Ba}^{2+}$ cations for using as radioactive waste encapsulation. Nature and Sci, 11, 148-155. (2013). http://www.sciencepub.net/nature. [59] Waly, E.-S. A., Fusco, M. A., \& Bourham, M. A. Gamma-ray mass attenuation coefficient and half value layer factor of some oxide glass shielding materials. Annals of Nuclear Energy, 96, 26-30. (2016). DOI: 10.1016/j.anucene.2016.05.028

[60] Tekin, H. O., Kavaz, E., Papachristodoulou, A., Kamislioglu, M., Agar, O., Altunsoy Guclu, E. E., Sayyed, M. I. Characterization of $\mathrm{SiO} 2-\mathrm{PbO}-\mathrm{CdO}-\mathrm{Ga}_{2} \mathrm{O}_{3}$ glasses for comprehensive nuclear shielding performance: Alpha, proton, gamma, neutron radiation. Ceramics International 45, 19206-19222, (2019) DOI: 10.1016/j.ceramint.2019.06.168

[61] Rammah, Y. S., Abouhaswa, A. S., Sayyed, M. I., Tekin, H. O., \& El-Mallawany, R. Structural, UV and shielding properties of ZBPC glasses. Journal of Non-Crystalline Solids. DOI: 10.1016/j.jnoncrysol.2018.12.013

[62] Kavaz, E., Tekin, H. O., Agar, O., Altunsoy, E. E., Kilicoglu, O., Kamislioglu, M., Sayyed, M. I. The Mass stopping power / projected range and nuclear shielding behaviors of barium bismuth borate glasses and influence of cerium oxide. Ceramics International 45, 1534815357, (2019) doi: 10.1016/j.ceramint.2019.05.028

[63] Issa, S. A. M., Saddeek, Y. B., Tekin, H. O., Sayyed, M. I., \& Shaaban, K. saber. Investigations of radiation shielding using Monte Carlo method and elastic properties of $\mathrm{PbO}-$ $\mathrm{SiO}_{2}-\mathrm{B}_{2} \mathrm{O}_{3}-\mathrm{Na}_{2} \mathrm{O}$ glasses. Current Applied Physics, 18(6), 717-727. (2018). DOI: 10.1016/j.cap.2018.02.018

[64] Issa, S. A. M., Tekin, H. O., Elsaman, R., Kilicoglu, O., Saddeek, Y. B., \& Sayyed, M. I. Radiation shielding and mechanical properties of $\mathrm{Al}_{2} \mathrm{O}_{3}-\mathrm{Na}_{2} \mathrm{O}-\mathrm{B}_{2} \mathrm{O}_{3}-\mathrm{Bi}_{2} \mathrm{O}_{3}$ glasses using MCNPX Monte Carlo code. Materials Chemistry and Physics. 223, 1 ,209-219 (2019), DOI: 10.1016/j.matchemphys.2018.10.064 
[65] Tekin, H. O., Kilicoglu, O., Kavaz, E., Altunsoy, E. E., Almatari, M., Agar, O., \& Sayyed, M. I. The investigation of gamma-ray and neutron shielding parameters of $\mathrm{Na}_{2} \mathrm{O}-\mathrm{CaO}-\mathrm{P}_{2} \mathrm{O}_{5^{-}}$ $\mathrm{SiO}_{2}$ bioactive glasses using MCNPX code. Results in Physics 12 1797-1804. (2019). DOI: 10.1016/j.rinp.2019.02.017

[66] Kaur, P., Singh, D., \& Singh, T. Heavy metal oxide glasses as gamma rays shielding material. Nuclear Engineering and Design, 307, 364-376. (2016). doi: 10.1016/j.nucengdes.2016.07.029

[67] Sayyed, M.I., Laariedh, F., Kumr, A. et al. Experimental studies on the gamma photonsshielding competence of $\mathrm{TeO}_{2}-\mathrm{PbO}-\mathrm{BaO}-\mathrm{Na}_{2} \mathrm{O}-\mathrm{B}_{2} \mathrm{O}_{3}$ glasses. Appl. Phys. A 126, 4 (2020). https://doi.org/10.1007/s00339-019-3182-8

[68] Agar O, Sayyed MI, Tekin HO, Kaky KM, Baki SO, Kityk I. An investigation on shielding properties of $\mathrm{BaO}, \mathrm{MoO}_{3}$ and $\mathrm{P}_{2} \mathrm{O}_{5}$ based glasses using MCNPX code.

Results Phys 2019; 12:629-34. https://doi.org/10.1016/j.rinp.2018.12.003

[69] Rammah, Y.S., El-Agawany, F.I., Mahmoud, K.A. et al. FTIR, UV-Vis-NIR spectroscopy, and gamma rays shielding competence of novel $\mathrm{ZnO}$-doped vanadium borophosphate glasses. J Mater Sci: Mater Electron (2020). https://doi.org/10.1007/s10854$\underline{020-03440-5}$

[70] Matori, K. A., Sayyed, M. I., Sidek, H. A. A., Zaid, M. H. M., \& Singh, V. P. Comprehensive study on physical, elastic and shielding properties of lead zinc phosphate glasses. Journal of Non-Crystalline Solids, 457, 97-103. (2017). DOI: 10.1016/j.jnoncrysol.2016.11.029

[71] Rammah, Y. S., Mahmoud, K. A., Kavaz, E., Kumar, A., \& El-Agawany, F. I. The role of $\mathrm{PbO} / \mathrm{Bi}_{2} \mathrm{O}_{3}$ insertion on the shielding characteristics of novel borate glasses. Ceramics International. (2020). DOI: 10.1016/j.ceramint.2020.04.018 
Figures

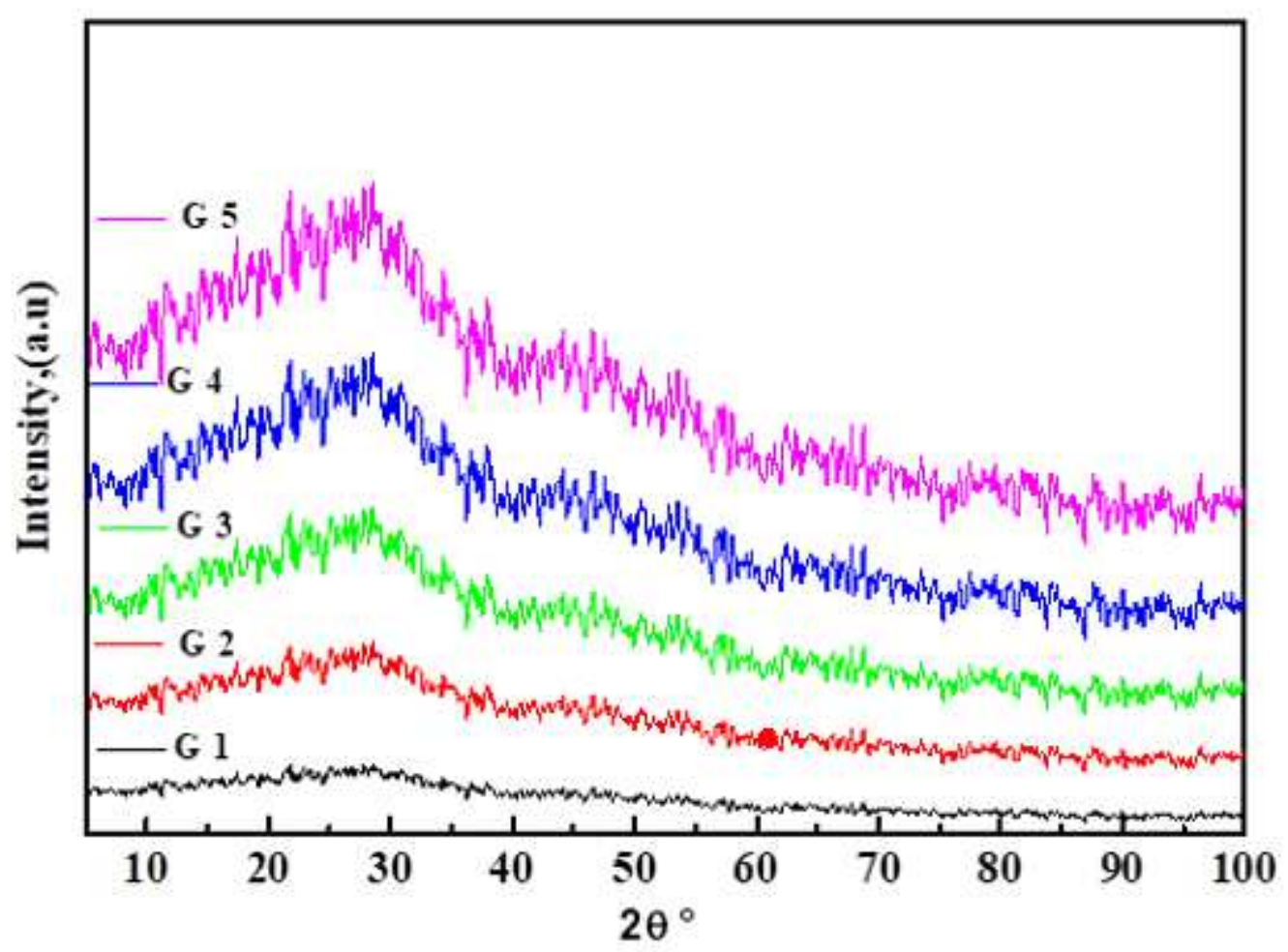

Figure 1

$\mathrm{XRD}$ of the studied glasses.

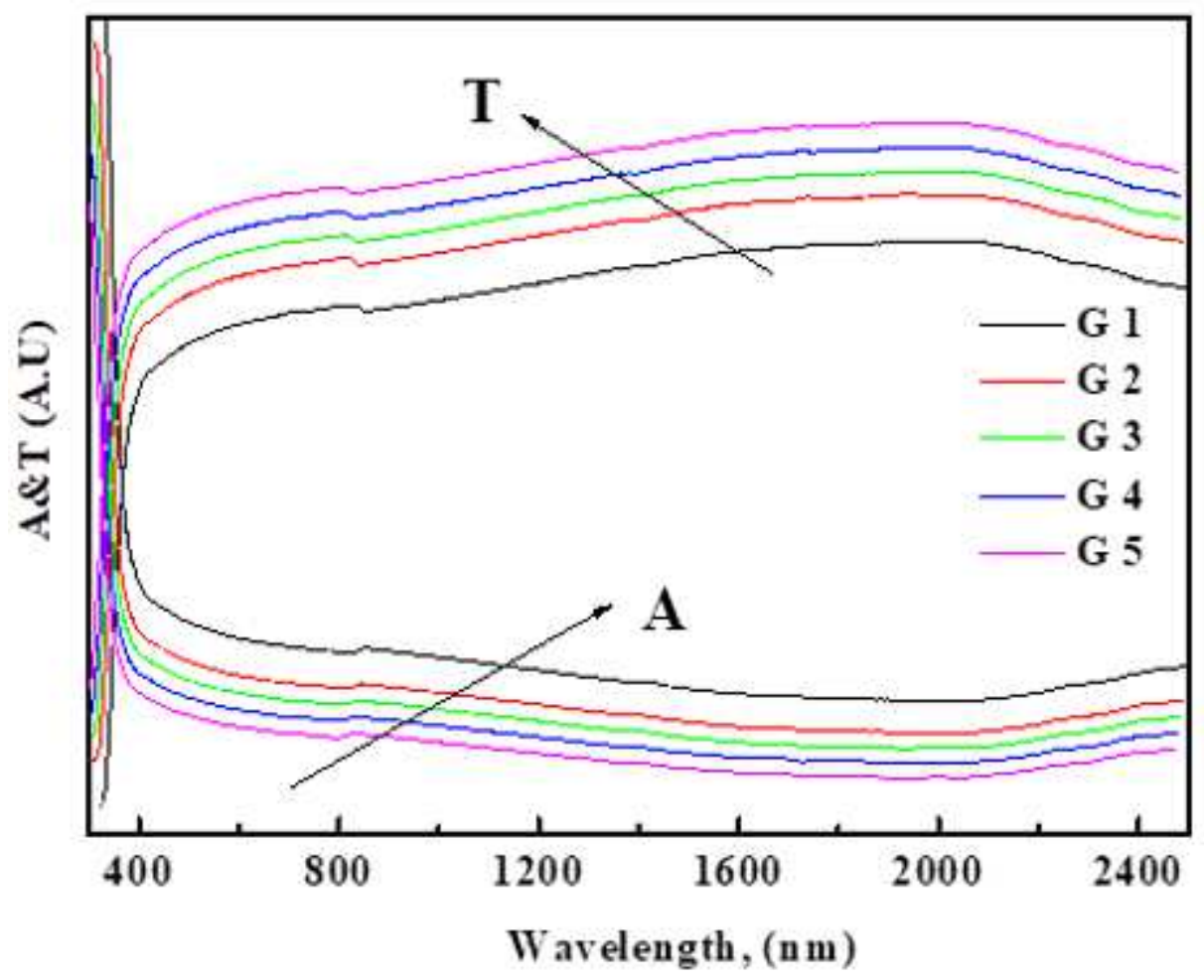


Figure 2

The absorbance (A) and Transmittance (T) of the prepared glasses.

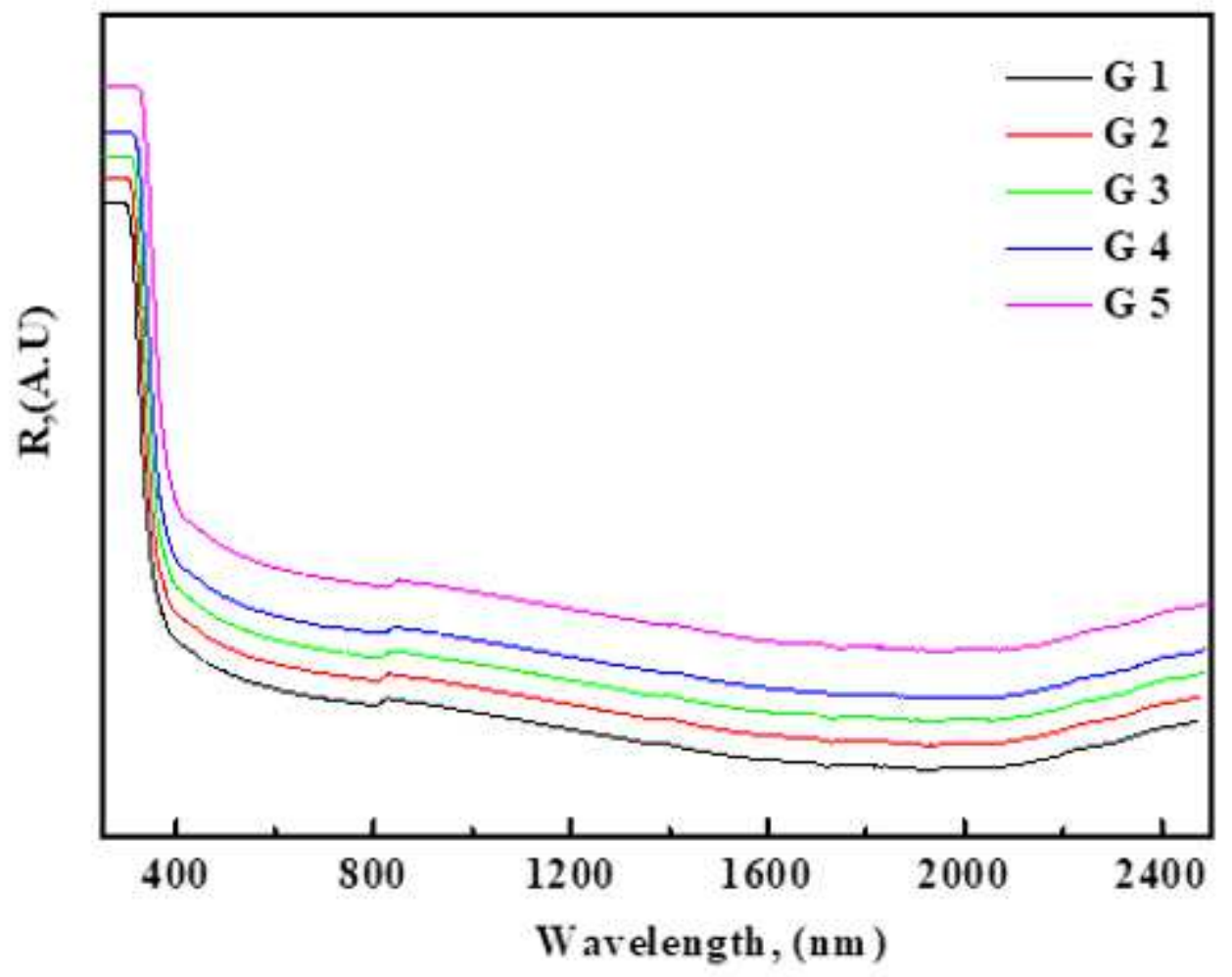

Figure 3

The reflectance $(R)$ of the prepared glasses.

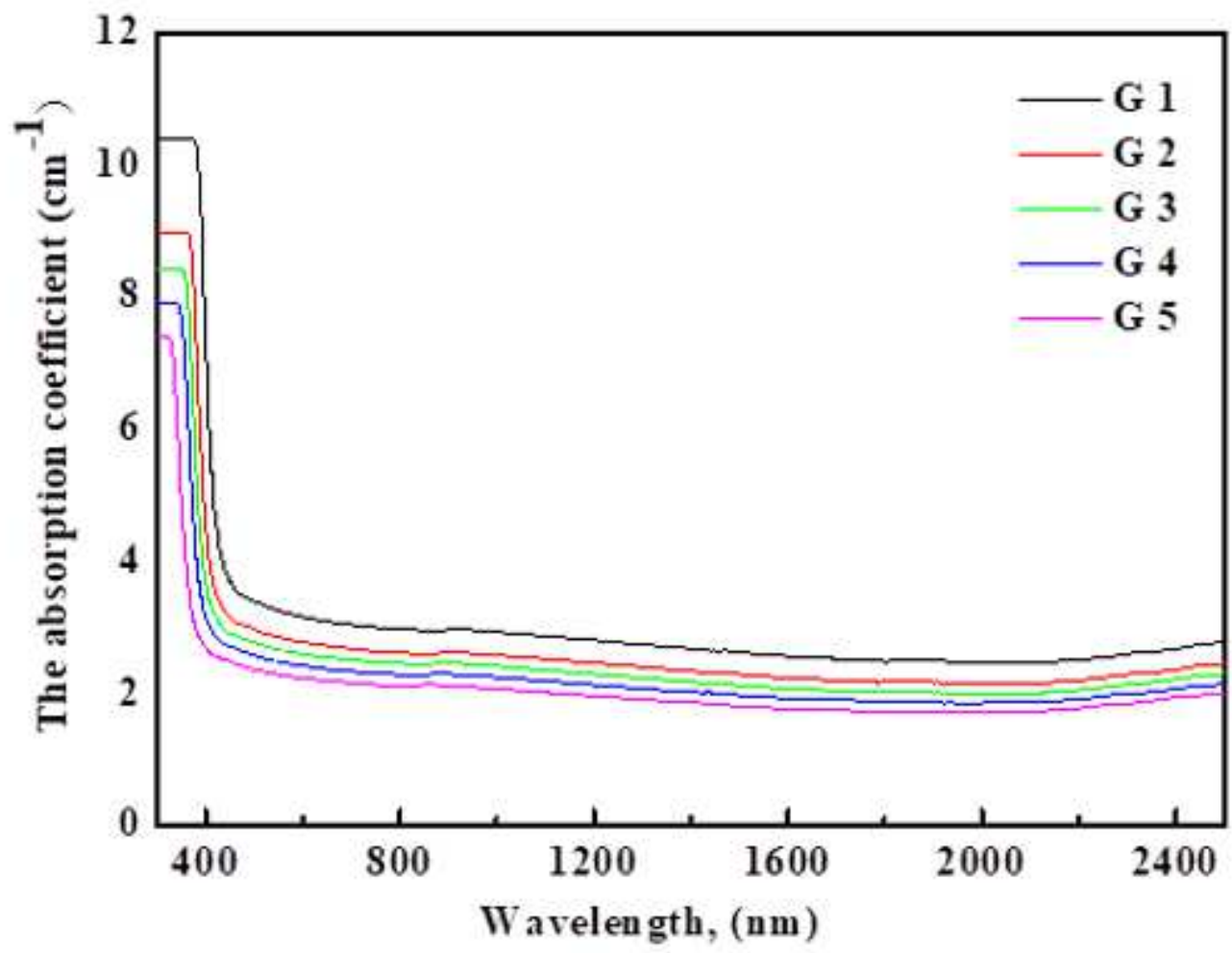


Figure 4

The absorption coefficient of the prepared glasses.

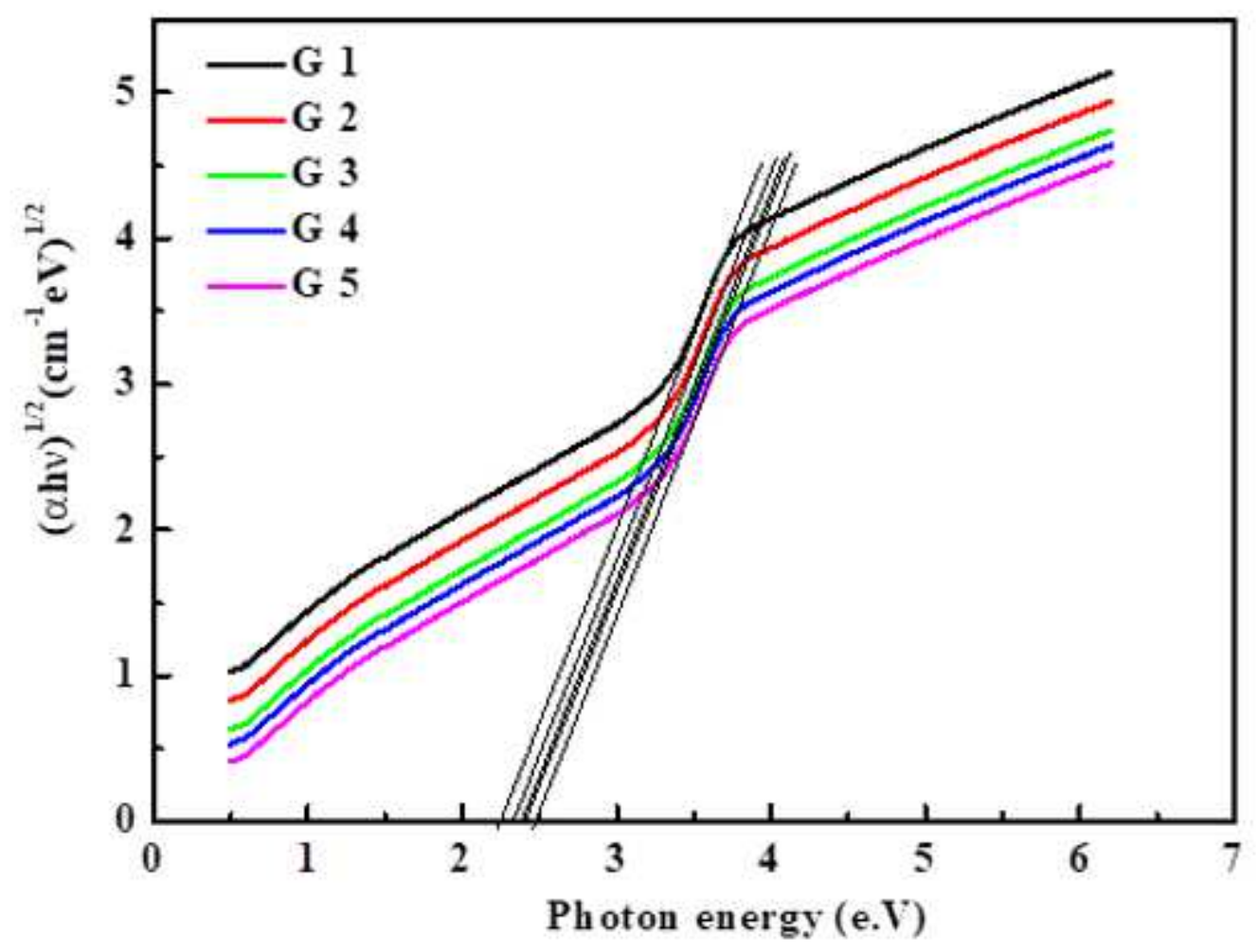

Figure 5

Plot of (a hu) $1 / 2$ against photon energy (hu) to calculate the indirect optical band gap from the intercept of the curves. 


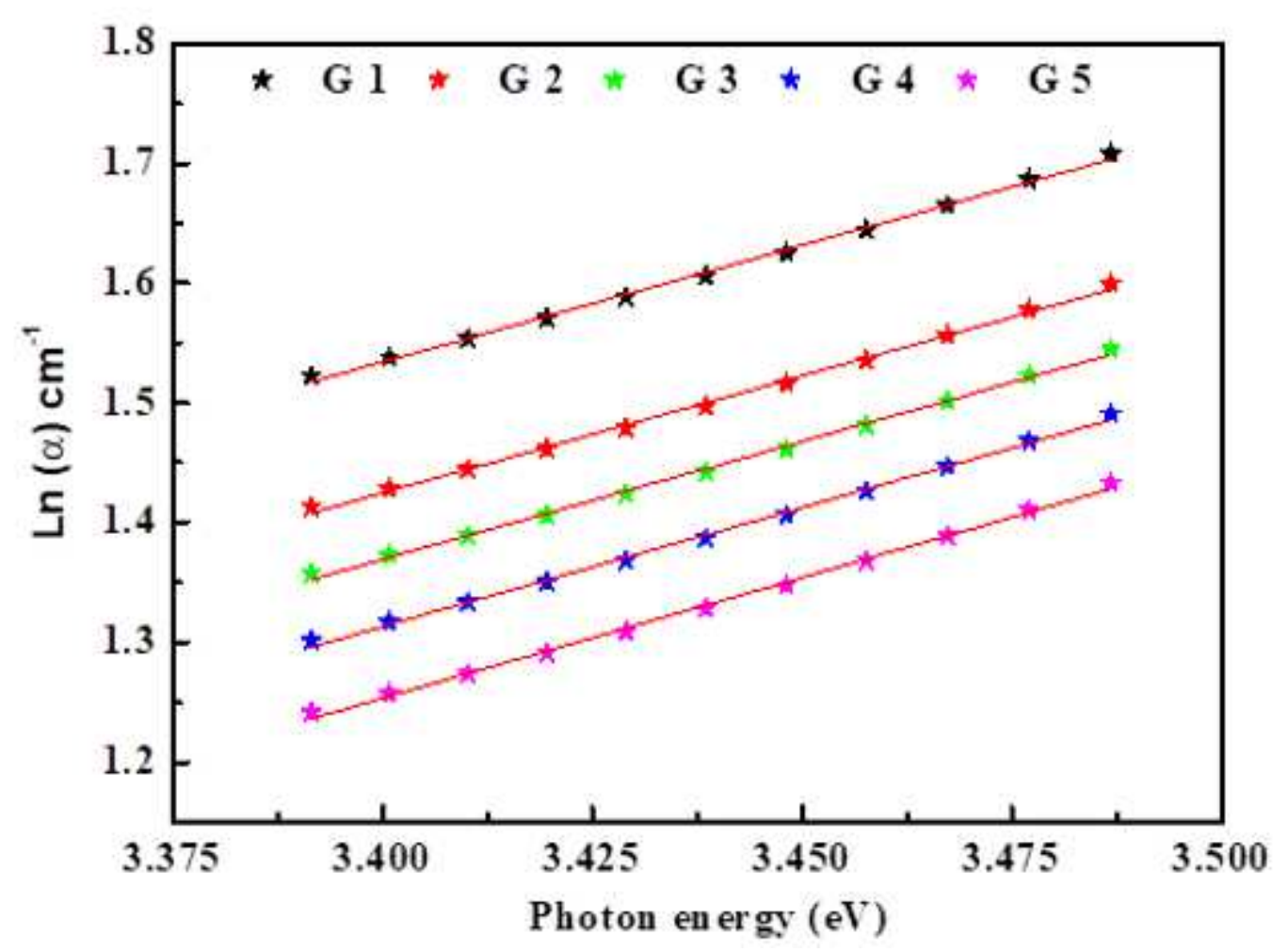

Figure 6

Dependence of $\ln (\mathrm{a})$ upon the photon energy (hu) for the prepared glasses.

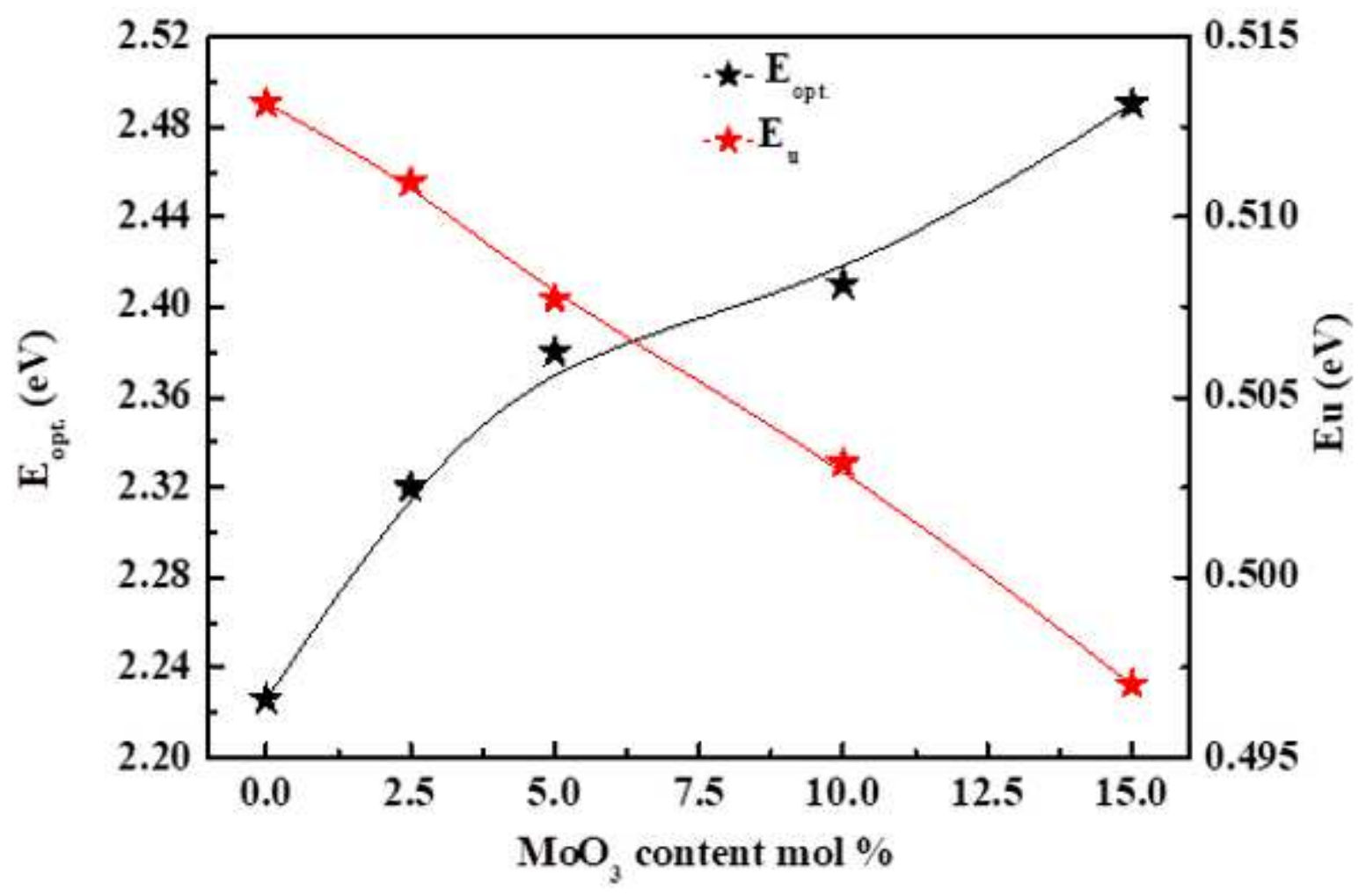

Figure 7

Optical band gap and Urbach energy versus concentration of MoO3. 


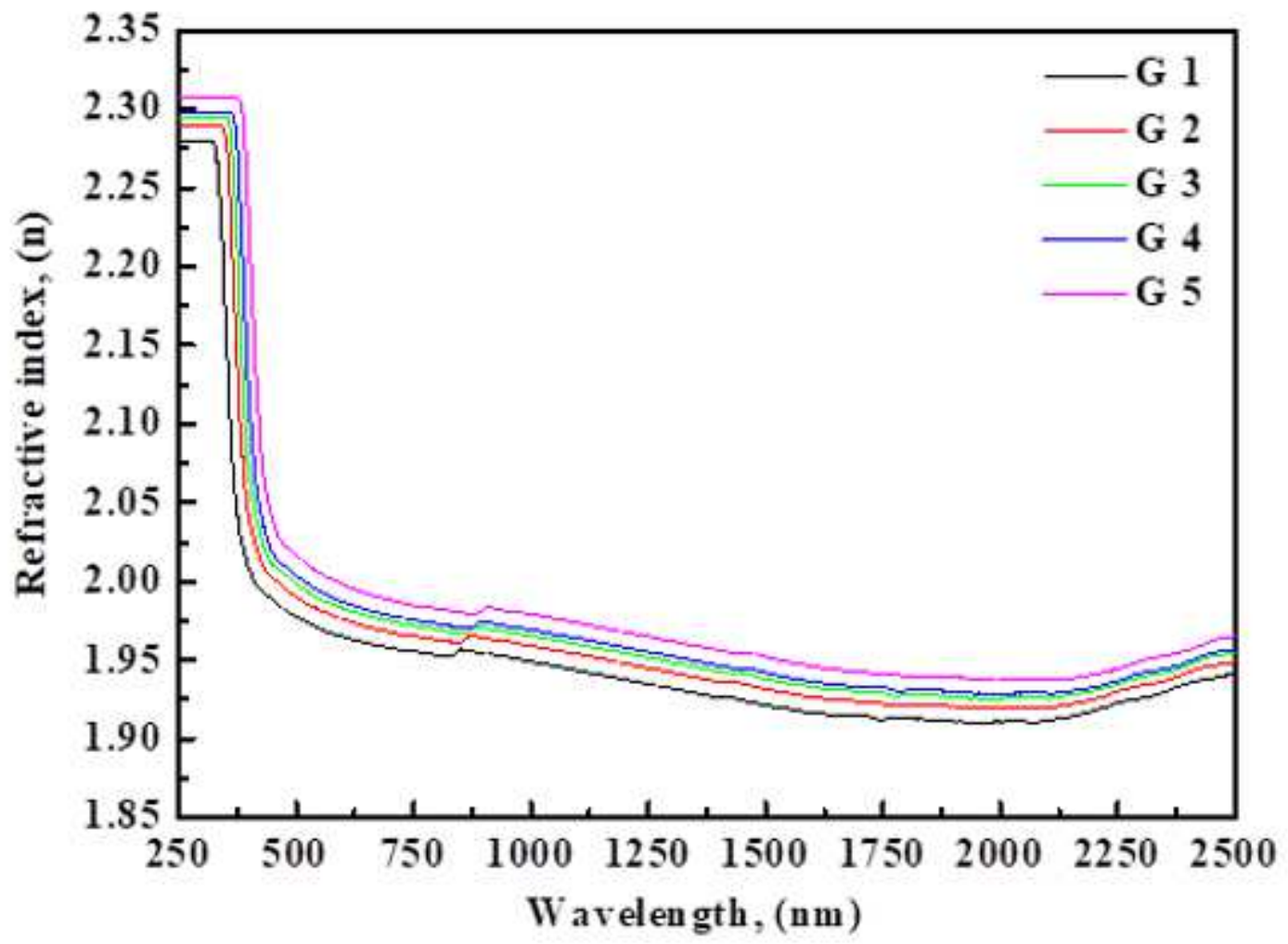

Figure 8

Refractive index of the prepared glasses.

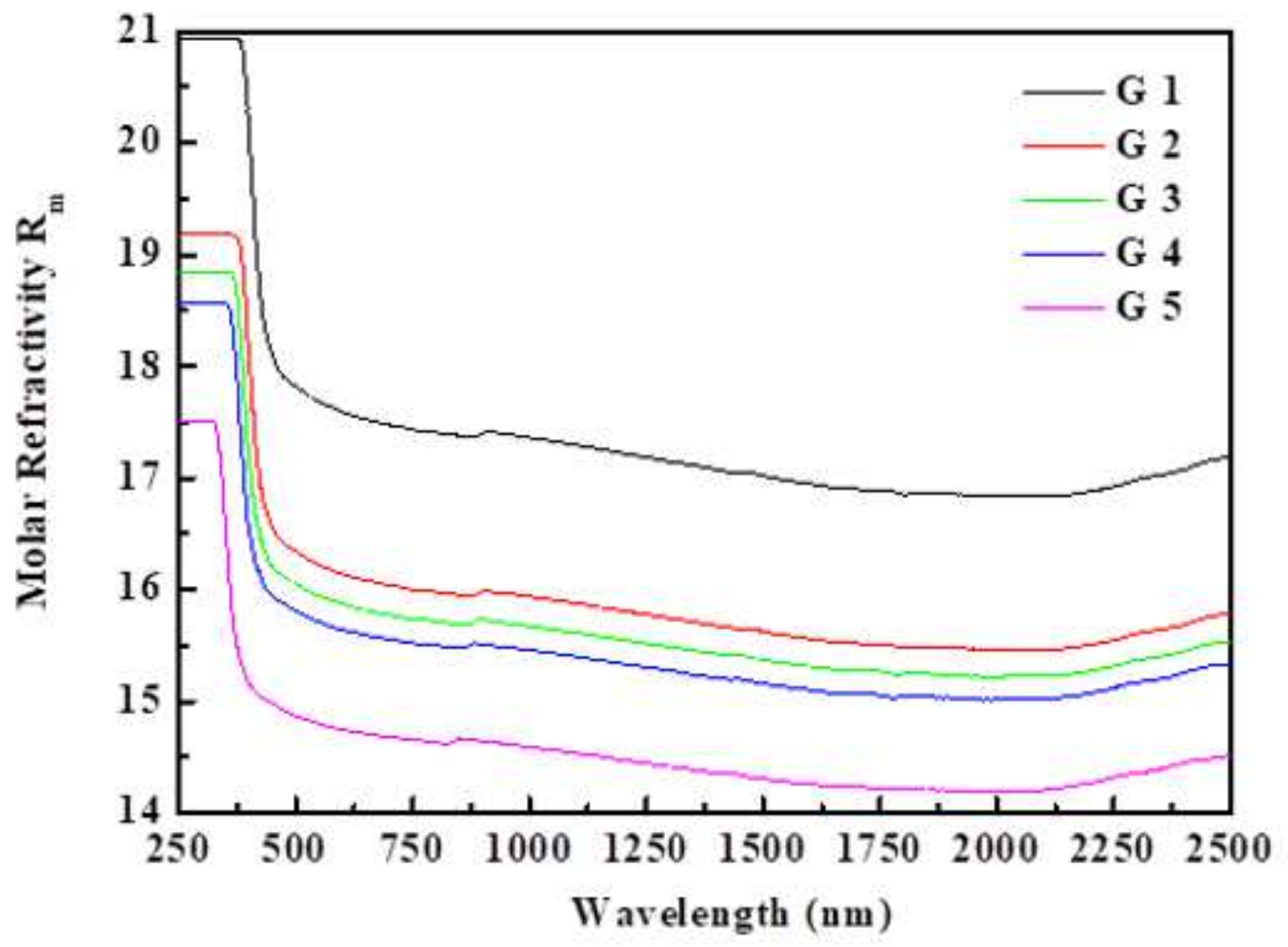

Figure 9

Molar refractivity of the prepared glasses. 


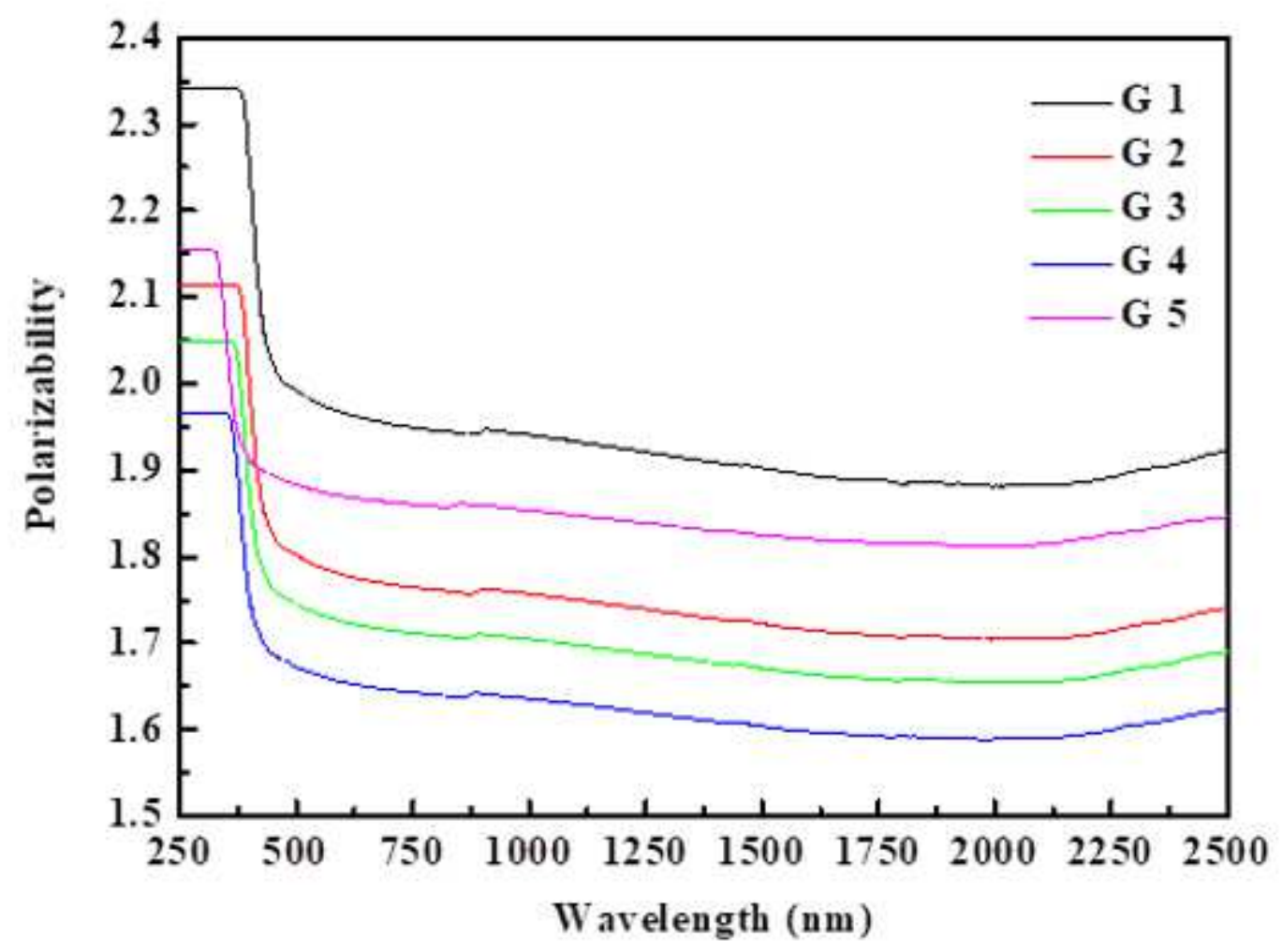

Figure 10

Electronic polarizability of the prepared glasses.

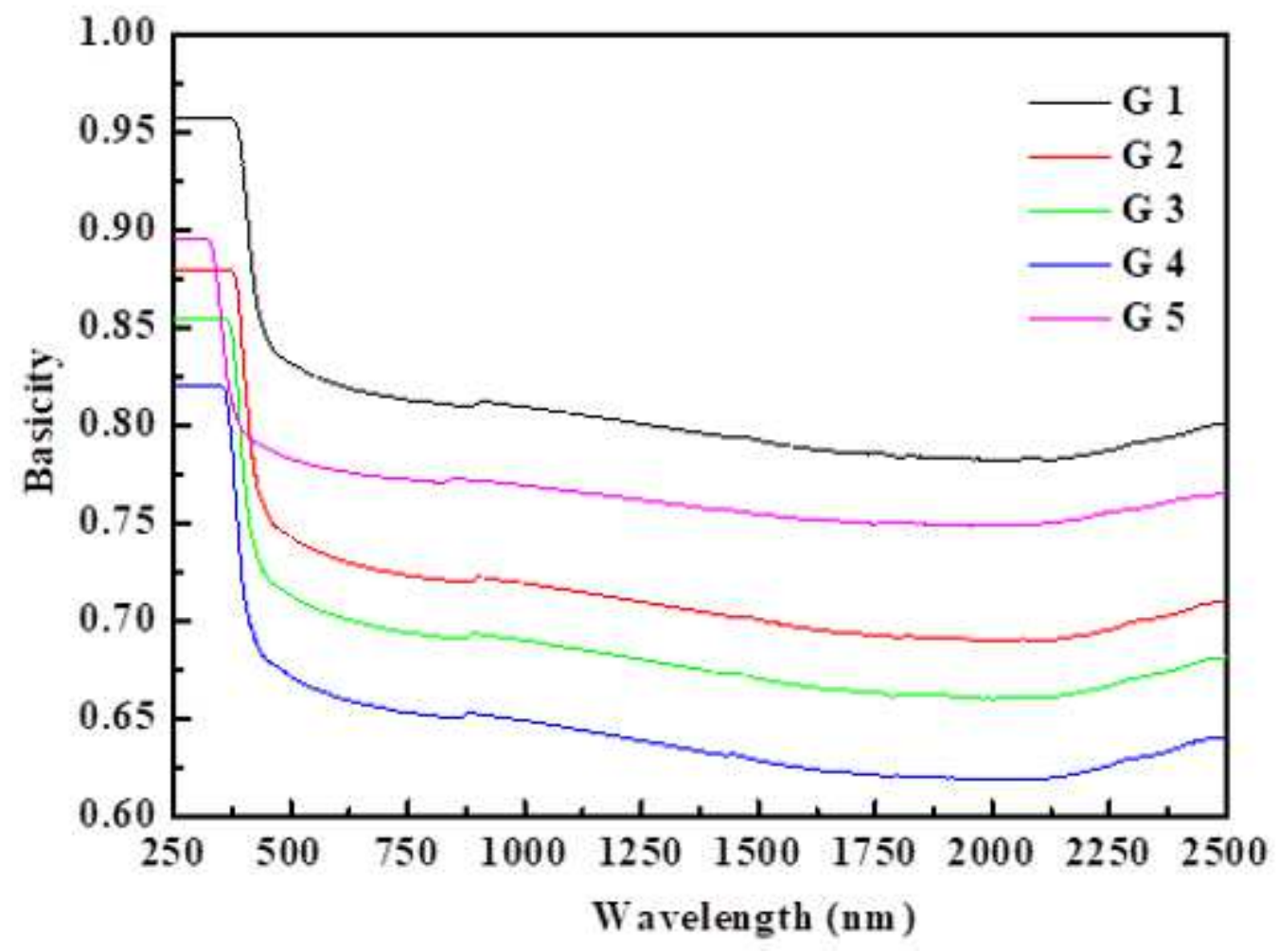

Figure 11 
Optical basicity of the prepared glasses.

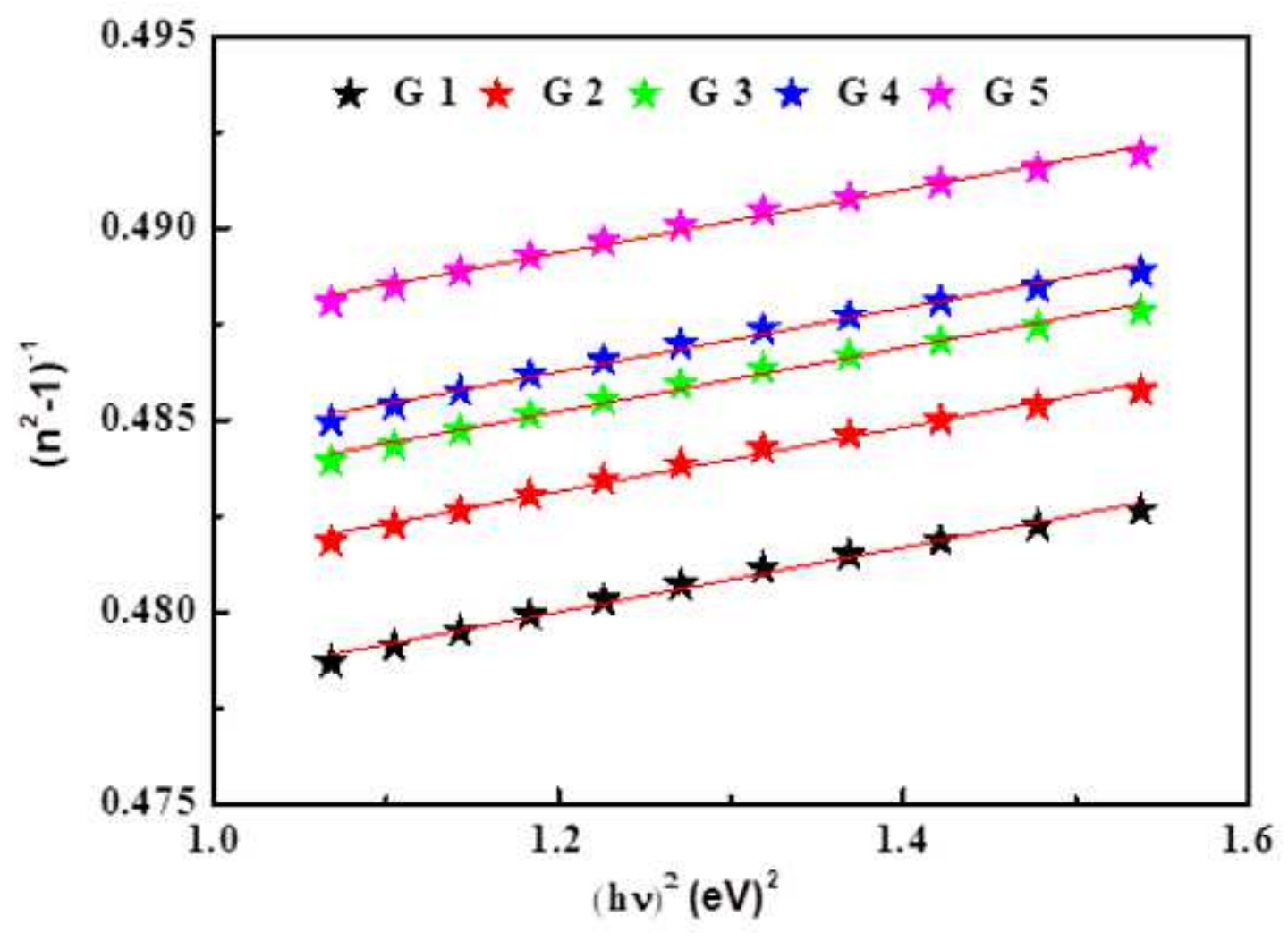

Figure 12

Variation of (n2-1)-1 with (hu)2 for the prepared glasses.

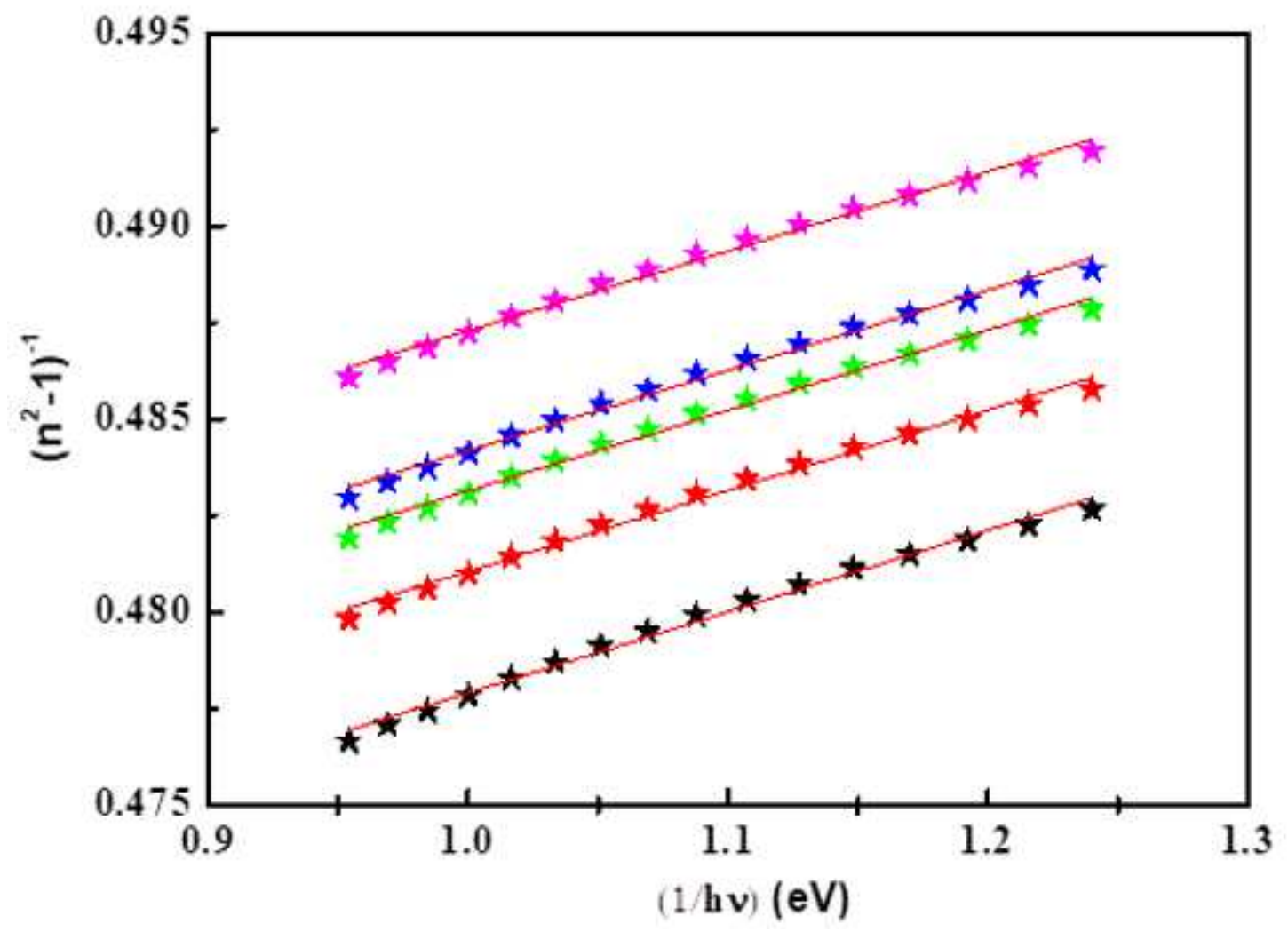


Figure 13

Variation of (n2-1)-1 with 1/(hu) for the prepared glasses.

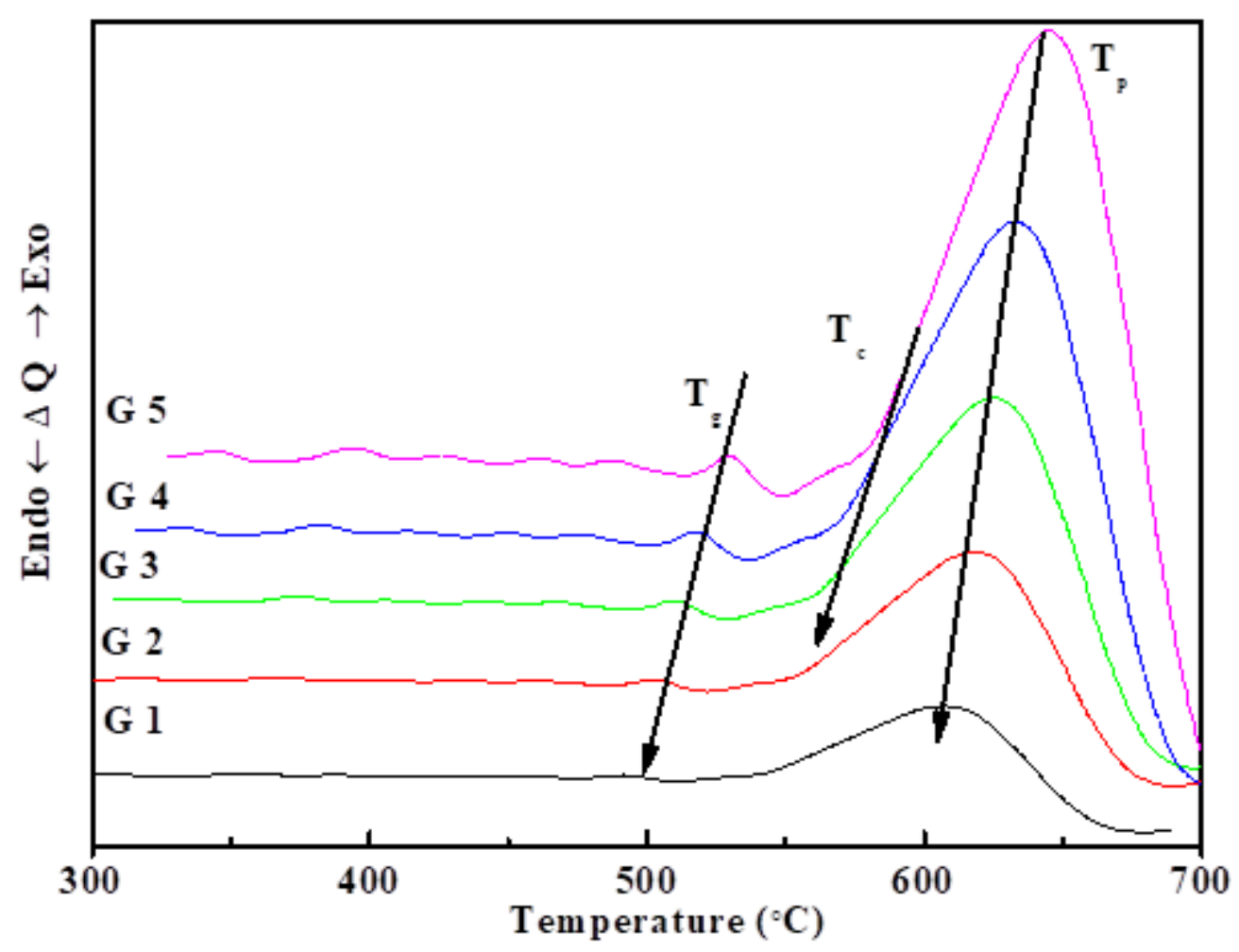

Figure 14

DTA of the prepared glasses. 


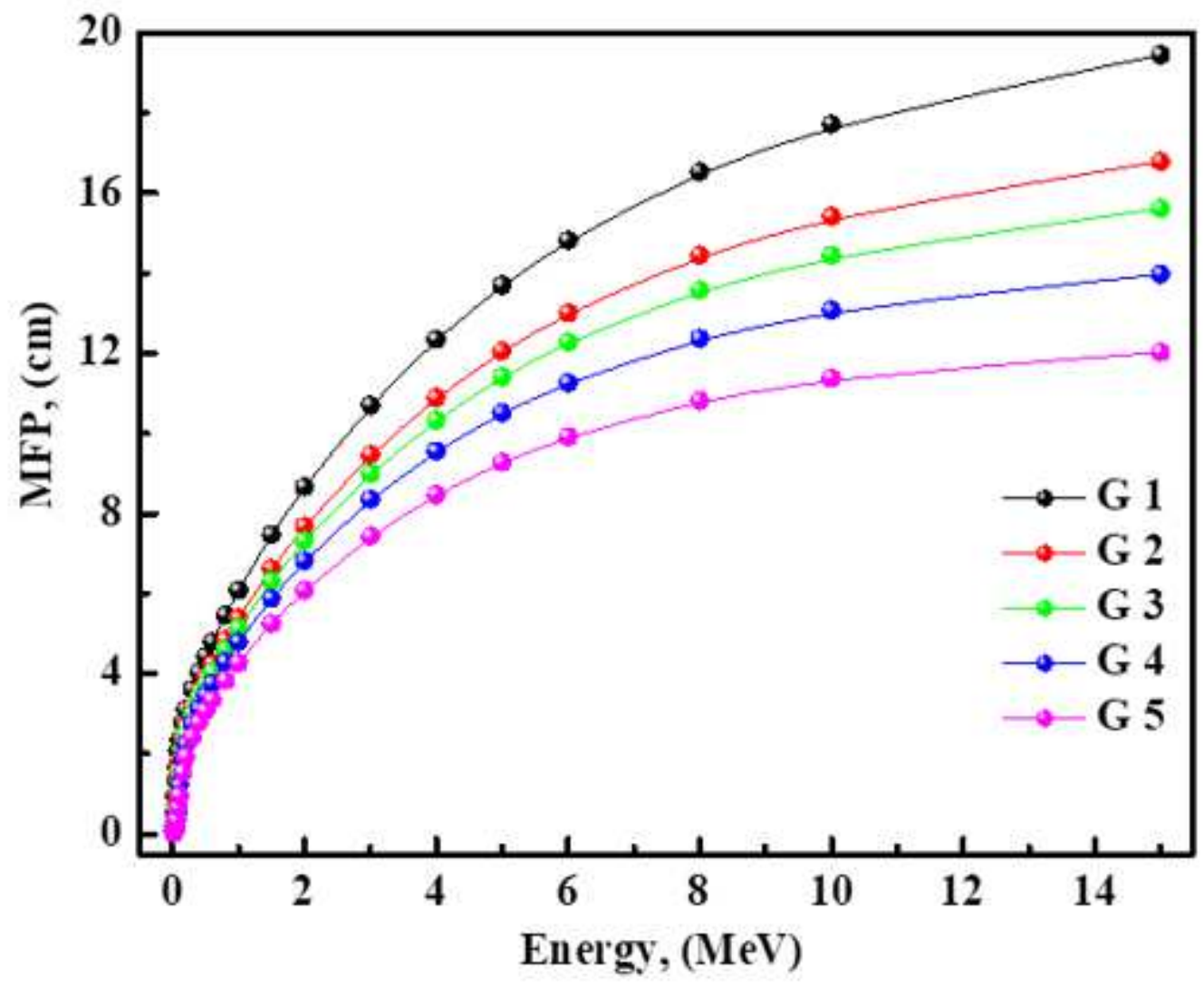

Figure 15

The MFP for the prepared glasses as a function of photon energy.

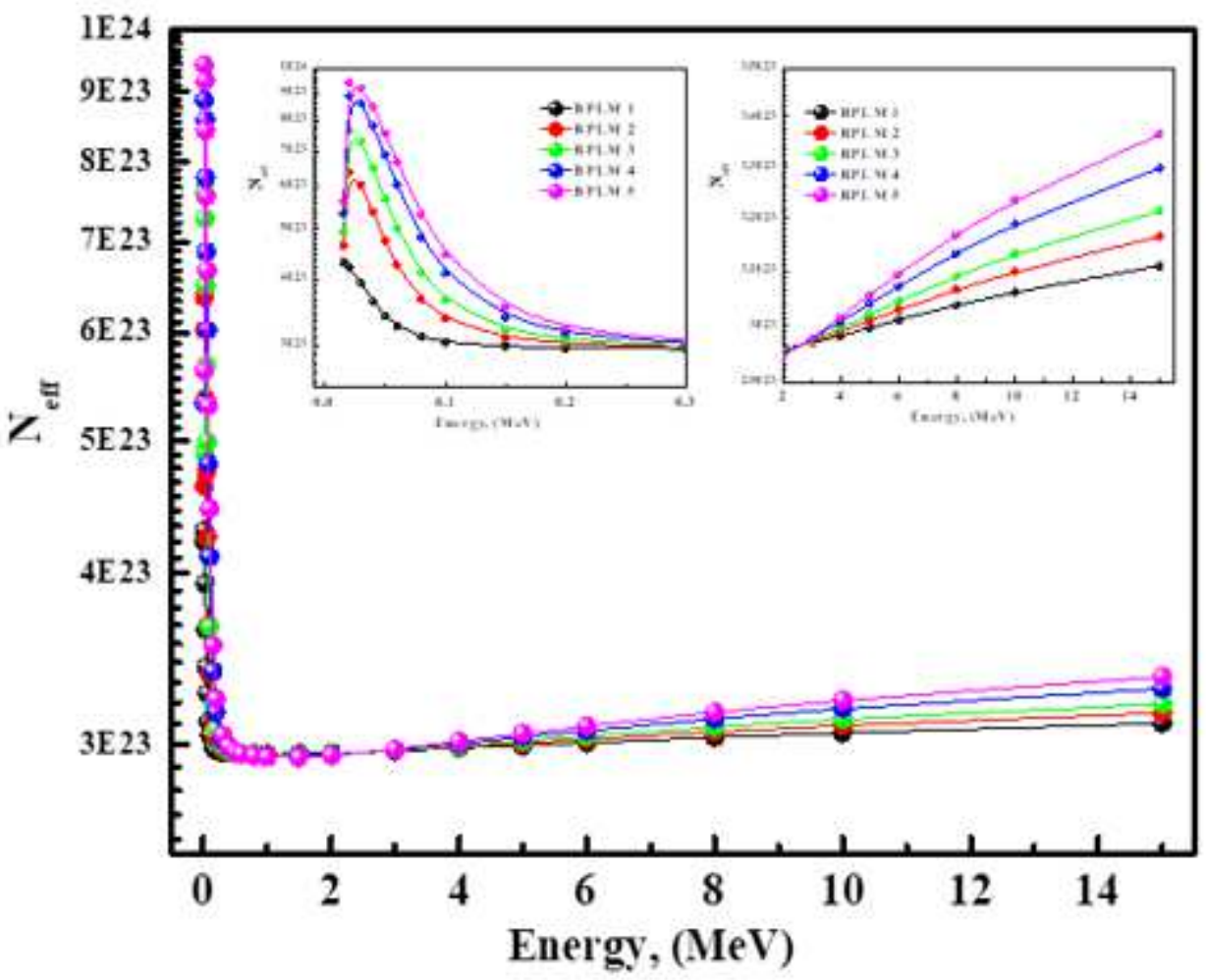

Figure 16 
The (Neff) for the prepared glasses as a function of photon energy.

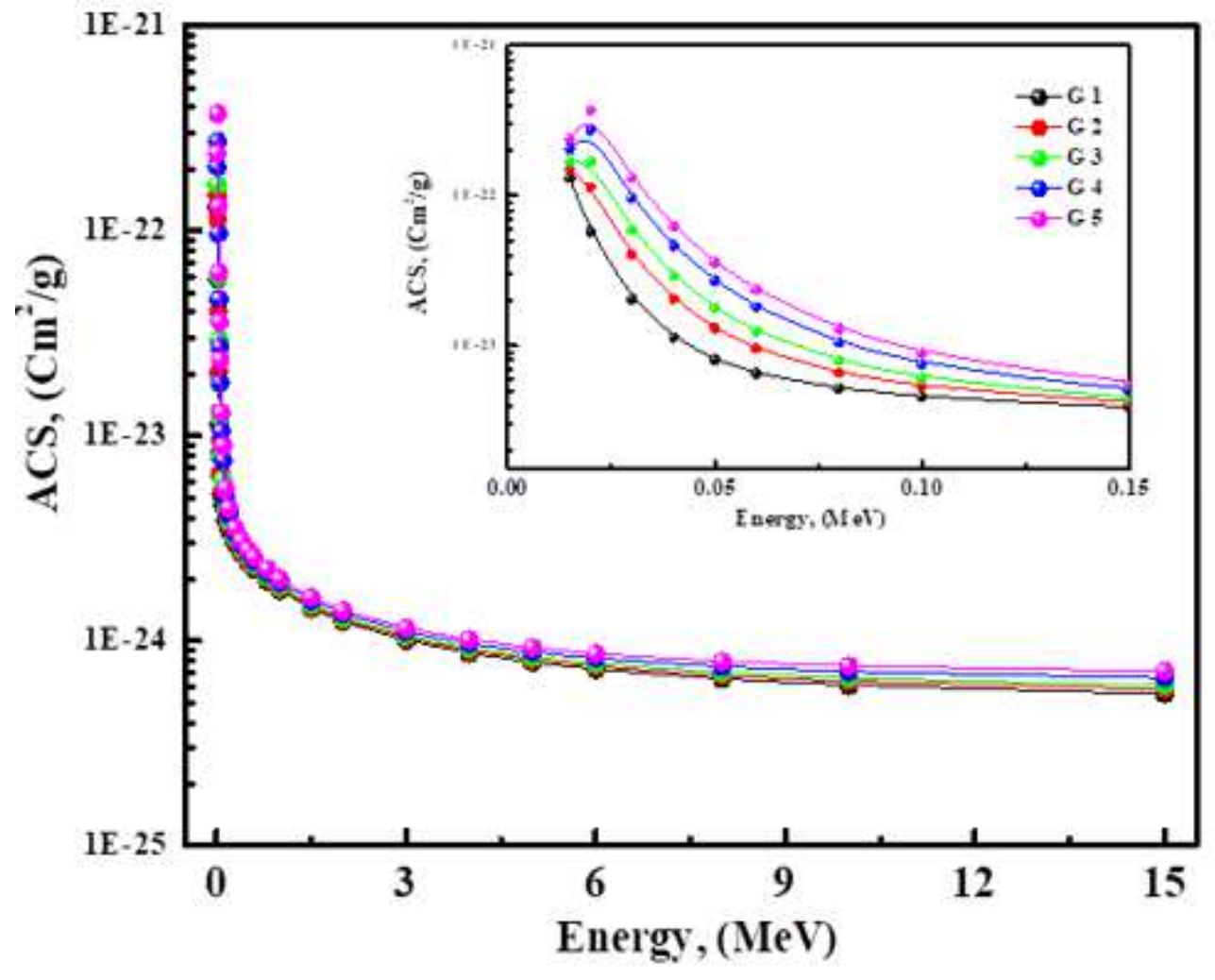

Figure 17

The ASC for the prepared glasses as a function of photon energy

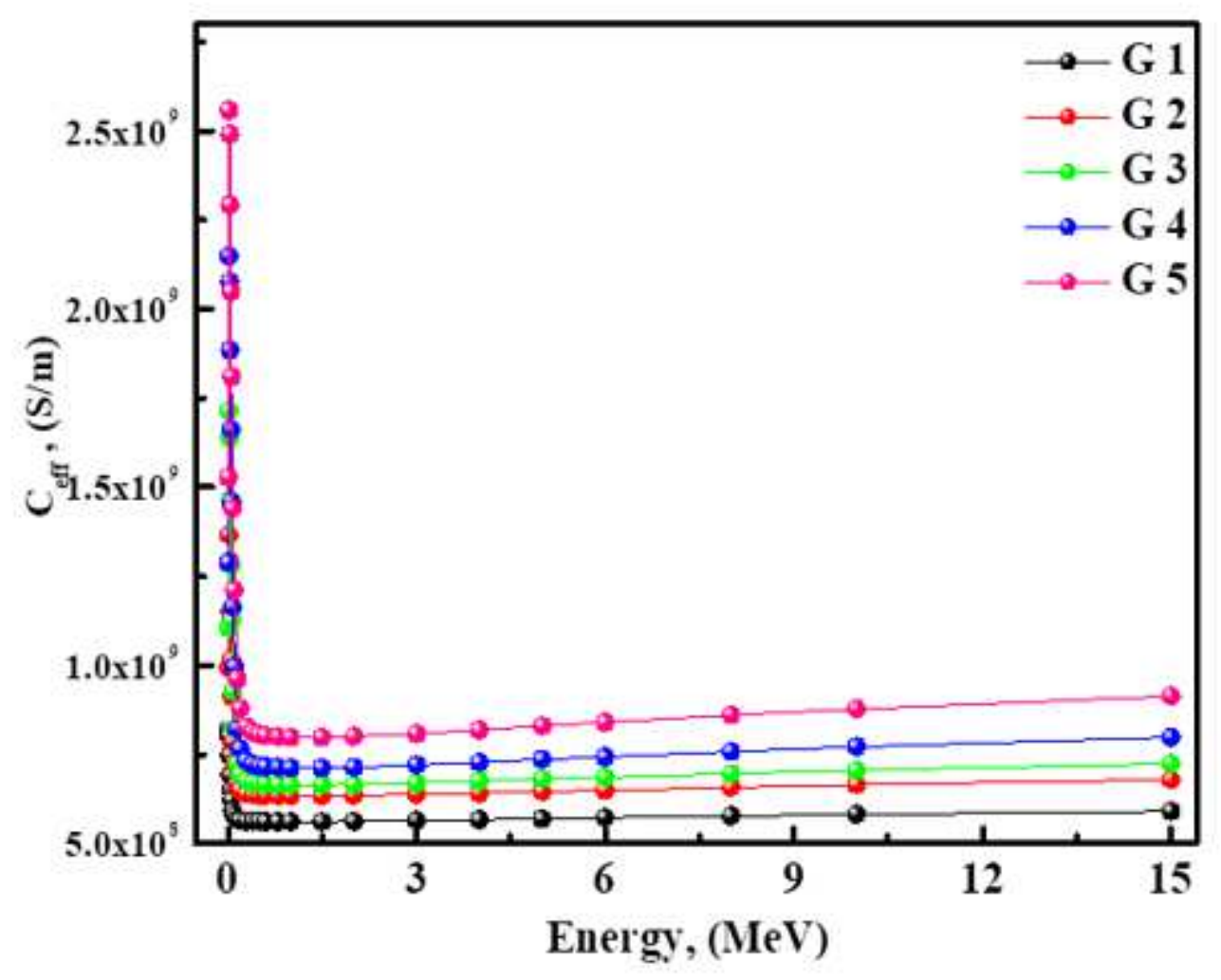

Figure 18 
The Ceff for the prepared glasses as a function of photon energy.
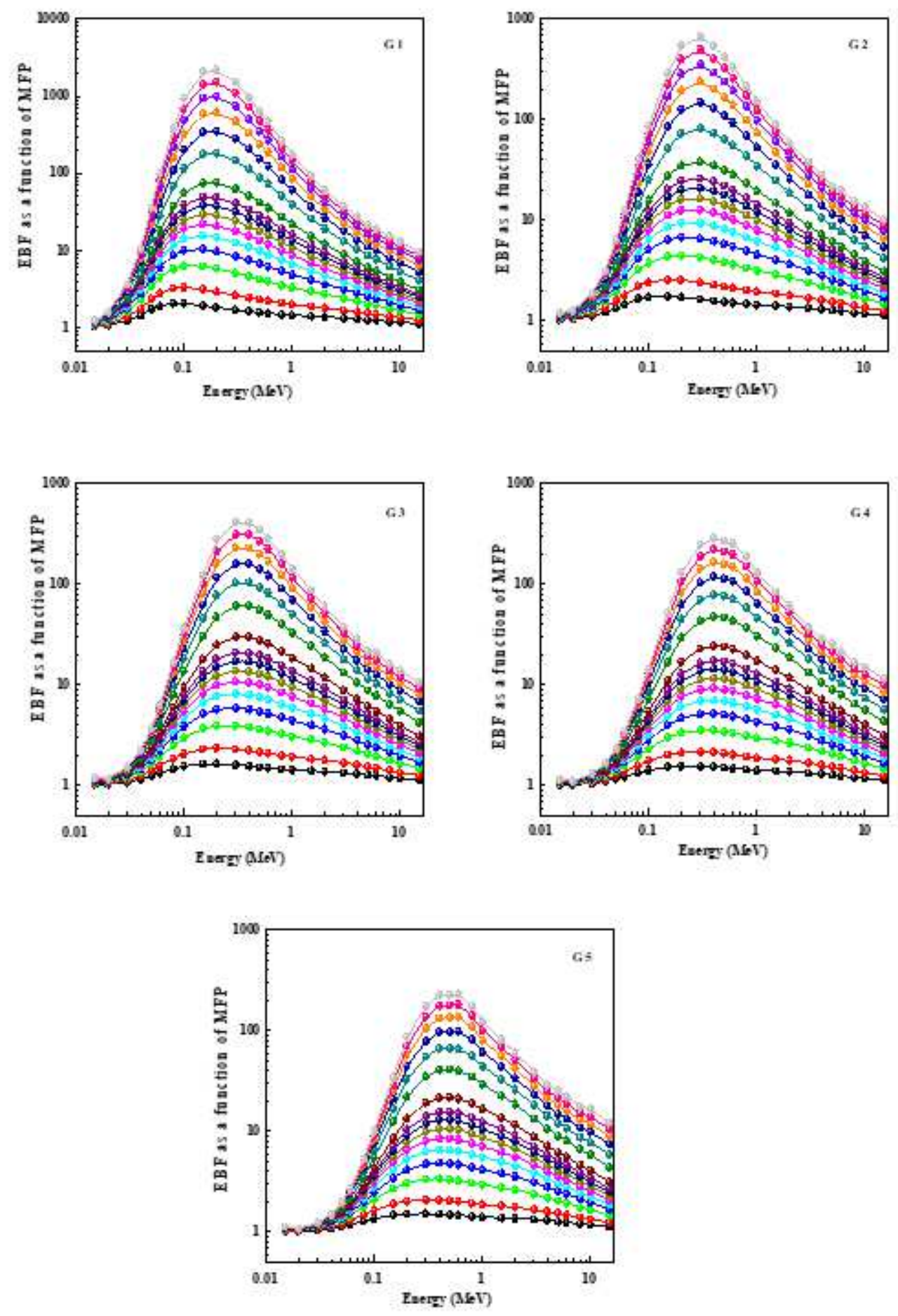

Figure 19

Variation of EBF versus the gamma ray energy for the prepared glasses as a function of photon energy. 

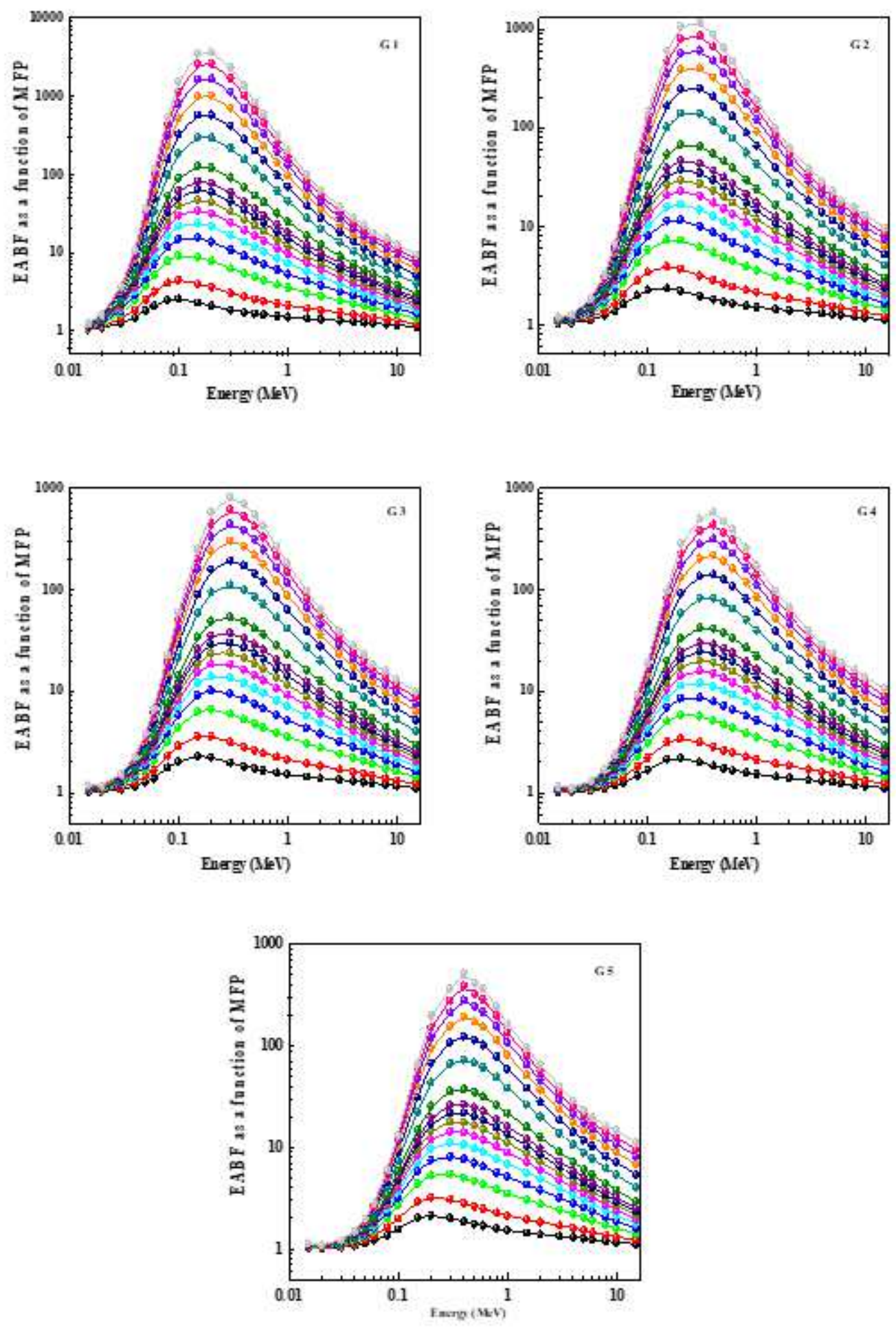

Figure 20

Variation of EABF versus the gamma ray energy for the prepared glasses as a function of photon energy. 


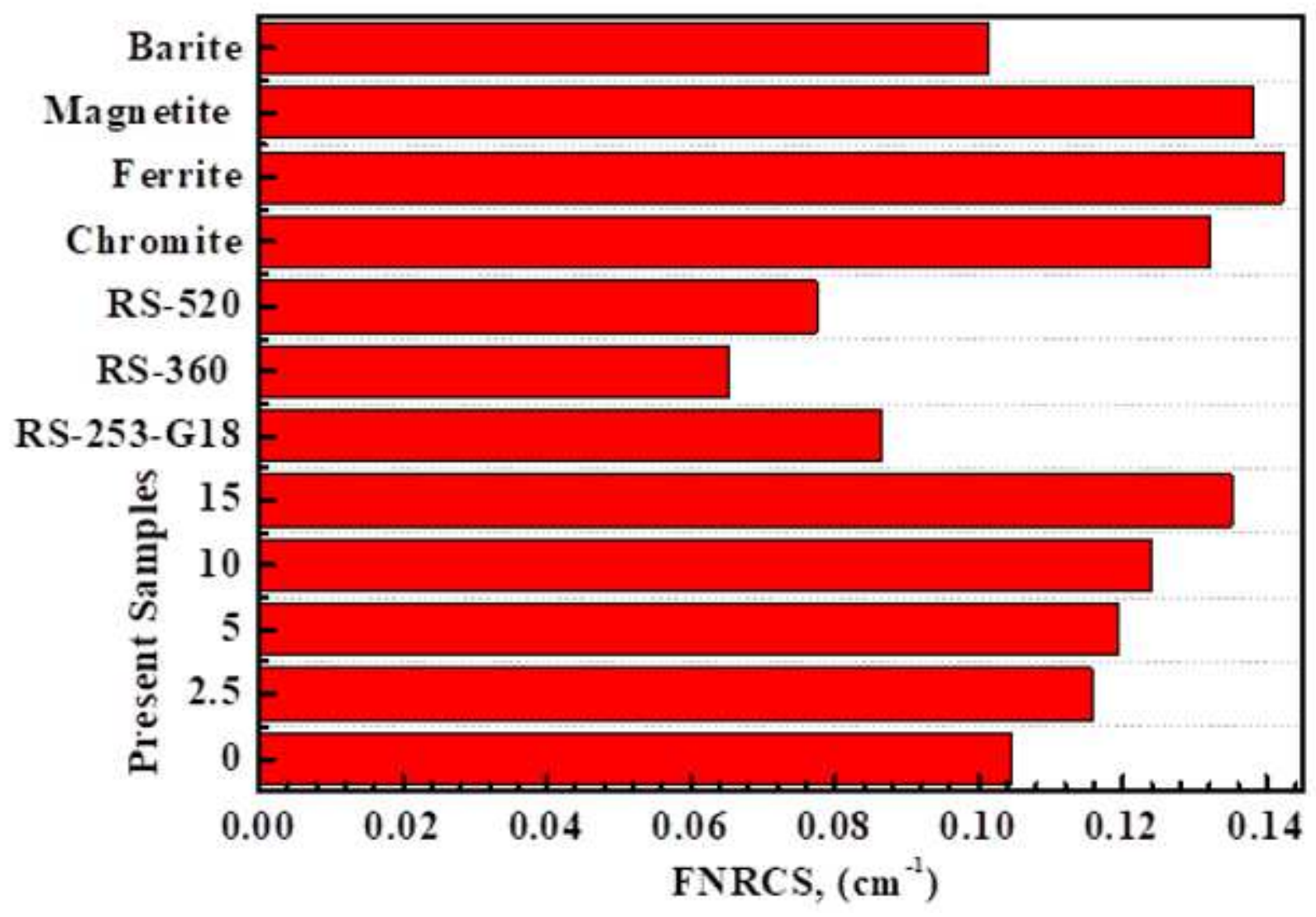

Figure 21

FNRCS for the prepared glasses comparison with standard materials. 